\title{
SOX2 Regulates Neuronal Differentiation of the Suprachiasmatic Nucleus
}

\author{
Arthur H. Cheng ${ }^{1,2} \oplus$, Samuel W. Fung ${ }^{1}\left(\mathbb{D}\right.$, Sara Hegazi ${ }^{1,2}$, Osama Hasan Mustafa Hasan Abdalla ${ }^{1,2}$ \\ and Hai-Ying Mary Cheng ${ }^{1,2, * \mathbb{D}}$ \\ 1 Department of Biology, University of Toronto Mississauga, Mississauga, ON L5L 1C6, Canada; \\ ahh.cheng@mail.utoronto.ca (A.H.C.); samuel.fung@mail.utoronto.ca (S.W.F.); \\ sara.hegazi@mail.utoronto.ca (S.H.); osama.abdalla@mail.utoronto.ca (O.H.M.H.A.) \\ 2 Department of Cell \& Systems Biology, University of Toronto, Toronto, ON M5S 3G5, Canada \\ * Correspondence: haiying.cheng@utoronto.ca
}

check for updates

Citation: Cheng, A.H.; Fung, S.W.; Hegazi, S.; Abdalla, O.H.M.H.; Cheng, H.-Y.M. SOX2 Regulates Neuronal Differentiation of the Suprachiasmatic Nucleus. Int. J. Mol. Sci. 2022, 23, 229. https://doi.org/ 10.3390/ijms23010229

Academic Editor: Fuyuki Sato

Received: 23 November 2021

Accepted: 23 December 2021

Published: 26 December 2021

Publisher's Note: MDPI stays neutral with regard to jurisdictional claims in published maps and institutional affiliations.

Copyright: (C) 2021 by the authors. Licensee MDPI, Basel, Switzerland. This article is an open access article distributed under the terms and conditions of the Creative Commons Attribution (CC BY) license (https:// creativecommons.org/licenses/by/ $4.0 /)$

\begin{abstract}
In mammals, the hypothalamic suprachiasmatic nucleus (SCN) functions as the central circadian pacemaker, orchestrating behavioral and physiological rhythms in alignment to the environmental light/dark cycle. The neurons that comprise the SCN are anatomically and functionally heterogeneous, but despite their physiological importance, little is known about the pathways that guide their specification and differentiation. Here, we report that the stem/progenitor cell transcription factor, Sex determining region Y-box 2 (Sox2), is required in the embryonic SCN to control the expression of SCN-enriched neuropeptides and transcription factors. Ablation of Sox 2 in the developing SCN leads to downregulation of circadian neuropeptides as early as embryonic day (E) 15.5 , followed by a decrease in the expression of two transcription factors involved in SCN development, Lhx 1 and Six6, in neonates. Thymidine analog-retention assays revealed that Sox 2 deficiency contributed to reduced survival of SCN neurons during the postnatal period of cell clearance, but did not affect progenitor cell proliferation or SCN specification. Our results identify SOX2 as an essential transcription factor for the proper differentiation and survival of neurons within the developing SCN.
\end{abstract}

Keywords: suprachiasmatic nucleus; neuronal differentiation; development; circadian clock

\section{Introduction}

Many organisms have evolved endogenous circadian rhythms to anticipate challenges and opportunities arising from the Earth's daily cycles of light and darkness. In mammals, circadian rhythms are orchestrated by the suprachiasmatic nucleus (SCN), a bilateral structure located in the anterior hypothalamus. Unlike most other tissues, the SCN is an autonomous circadian pacemaker that can exhibit robust rhythmic oscillations for weeks, even when isolated and maintained ex vivo as organotypic slice cultures [1]. Dissociated SCN neuronal cultures further demonstrated that each neuron in the SCN network harbors a molecular clock machinery and is capable of independent cellular oscillations [2].

At the molecular level, circadian rhythms are generated by a series of transcriptiontranslation feedback loops (TTFLs) through a negative feedback mechanism. In the primary feedback loop, heterodimers of the transcription factors, CLOCK and BMAL1, drive the expression of core clock genes including Per and Cry through recognition of E-box elements within gene promoters [3-7]. Once translated, PER:CRY heterodimers inhibit CLOCK:BMAL1, thus repressing their own transcription. Eventual degradation of PER and CRY proteins results in the derepression of E-box-mediated transcription, permitting the initiation of a new round of gene expression [3,4,8-11]. In addition to the TTFLs, individual SCN neurons synthesize neuropeptides and neurotransmitters to coordinate endogenous oscillations and entrainment at the tissue level [12-14]. As the structure responsible for receiving and integrating time cues from the environment and for driving tissue-specific circadian oscillators through humoral and endocrine signaling, the SCN is regarded as the master circadian clock that dictates the rhythm of the organism $[15,16]$. 
The murine SCN is comprised of approximately 20,000 neurons, in addition to astrocytes, oligodendrocytes, endothelial cells, microglia, and polydendrocytes $[17,18]$. Neurons of the SCN can be further categorized into subtypes based on spatial distribution, circadian rhythmicity, light responsiveness, and the expression pattern of specific cellular markers including neuropeptides [17,19-22]. Given the heterogeneity of the SCN, its genesis and maturation are believed to be controlled by intricate developmental pathways. Transcription factors such as Six3, Six6, Lhx2, Vax1, and Foxd1 have been shown to be necessary for SCN specification [23-27]. However, to date, only one transcription factor, Lhx1, has been demonstrated to regulate SCN differentiation and the expression of SCN neuropeptides [28]. To advance our understanding of SCN development, we focused our attention on the transcription factor, SRY (sex-determining region Y)-box 2 (SOX2).

SOX2 is first expressed in the inner cell mass and the trophectoderm of the blastocyst, and is present in stem cells of different tissues during later developmental stages [29]. In the brain, SOX2 is highly expressed in neural progenitor cells, which constitute the ventricular zone of the developing neural tube [29]. As cells differentiate and move out of the neurogenic ventricular zone of the neural tube, they turn off the expression of SOX2 [29]. However, a few groups of post-mitotic, differentiated cells in the adult brain, including SCN neurons, retain robust SOX2 expression [30,31]. Previous studies have found that constitutive or conditional ablation of Sox2 results in varying degrees of developmental defects, depending on the timing and location of Sox 2 depletion. Sox 2 ablation at E9.5 in Foxg1-expressing cells leads to severe developmental defects in the telencephalon, including loss of the medial ganglionic eminence and olfactory neuroepithelium [32]. Deletion of Sox2 in Nestin-expressing cells results in the failure to maintain hippocampal radial glia and neurogenesis, culminating in the loss of the hippocampal dentate gyrus [33]. Sox 2 hypomorphic mice have reduced GABAergic interneurons in the newborn cortex and adult olfactory bulb, accompanied by increased neurodegeneration and impaired adult neurogenesis in the subventricular and subgranular zones [34,35]. These mice also exhibit reduced pituitary size and hormone production as well as testicular atrophy and infertility with age [36].

Using Vgat-cre transgenic mice to ablate Sox 2 expression in the SCN, we recently highlighted the key roles of SOX2 in regulating SCN circadian timekeeping $[37,38]$. Sox2 deletion impairs light-induced entrainment and the generation of robust, precise, and consolidated behavioral rhythms. RNA-seq analysis revealed marked changes in the circadian transcriptome of the adult SCN in the absence of SOX2; in particular, we noted significant downregulation of genes encoding core clock components, neuropeptides, neuropeptide receptors, and transcription factors with documented roles in development. Some of these transcriptional perturbations are likely to be through a direct interaction between SOX2 and the promoter or enhancer of the target gene in the adult $\mathrm{SCN}$, as was demonstrated for the Period2 gene. However, there may also be indirect mechanisms stemming from a potential impact of Sox 2 ablation on SCN development. Given that the SCN of Vgat-specific Sox 2 knockout mice was visibly smaller than Sox $2^{f l f l}$ littermates [37], it is plausible that Sox 2 deletion disrupted the development and/or maturation of the mutant SCN.

Here, we show that SOX2 is indispensable for the proper regulation of SCN neuronal differentiation and survival. We demonstrate that $V g a t$-driven Cre recombinase activity ablates SOX2 expression in the SCN at or before the onset of SCN neurogenesis. The absence of SOX2 does not impair cell proliferation during SCN neurogenesis, but instead leads to a significant reduction in the expression of arginine vasopressin (Avp) and vasoactive intestinal peptide (Vip) and the number of $\mathrm{Avp}^{+}$and $\mathrm{Vip}^{+}$cells in the SCN as early as E15.5. Notably, the downregulation of these neuropeptides precedes the decrease in expression of Six 6 and $L h x 1$. Other SCN-enriched neuropeptides such as prokineticin 2 (Prok2) and neuromedin S (Nms) are also downregulated in the neonatal, Sox2-ablated SCN, whereas transcription factors previously implicated in SCN specification and differentiation, including Six3, Vax1, Rora, and Rorb, are not affected. Moreover, the absence of SOX2 increases the numbers of SCN neurons that are normally lost during the early postnatal 
period. Taken together, our findings identify a critical role of SOX2 in the differentiation of SCN neurons, a role that appears to be functionally independent of Six6, Lhx1, and other transcription factors that have been implicated in SCN development.

\section{Results}

2.1. Sox2 Ablation in the Vgat-cre;Sox $2^{f l f l}$ Model Occurs at or before E12.5 and Is Restricted to the $S C N$

To determine when Sox2 gene excision occurs in the SCN of $V g a t-c r e ; S o x 2^{f l f l}$ mice, we mapped the activity of Cre recombinase by breeding Vgat-cre animals with the Rosa26-loxPSTOP-loxP-EYFP (Rosalfflf) strain, the latter expressing enhanced yellow fluorescent protein (EYFP) upon excision of the loxP-flanked STOP cassette [39]. The expression of EYFP was co-mapped with SOX2 in the brains of E13.5, E15.5, P0, and adult Vgat-cre;Rosa ${ }^{\text {fl/ }}$ mice (Figure 1A-H). Strong EYFP and SOX2 expression was detected by immunofluorescence (IF) in the ventral anterior hypothalamus of E13.5 embryos, and in E15.5, P0, and adult SCN (Figure 1E-H). Noticeably, from E13.5 onwards, EYFP and SOX2 expression was highly colocalized in the SCN, but not in nearby hypothalamic regions (Figure $1 \mathrm{E}-\mathrm{H}$ ). In fact, with the exception of the SCN, co-localization of EYFP and SOX2 was not observed in most brain regions (Figure 1A-D). Our results suggest that SOX2 ablation in the SCN of $V g a t-c r e ; S o x 2^{f l f l}$ mice might have occurred on or before E13.5, thus prompting us to profile an earlier developmental age to confirm the time of Sox2 ablation. To accomplish this, we characterized the expression of EYFP and SOX2 in $\mathrm{Vgat}$-cre;Sox $2^{f l / f l}$; Rosa $a^{f l /+}$ mice, where Sox 2 is conditionally ablated, and $V g a t-c r e ; S o x 2^{f l /+} ;$ Rosafl/+ control mice at E12.5 and E13.5 (Figure 2A,B). At both time points, EYFP and SOX2 were detected in the ventral anterior hypothalamus of $V g a t-c r e ; S o x 2^{f l /+} ;$ Rosafl/+ control embryos and their expression patterns showed moderate (E12.5) to strong (E13.5) colocalization (Figure 2A,B). In contrast, virtually no $\mathrm{EYFP}^{+} \mathrm{SOX}^{+}$cells were found in the ventral anterior hypothalamus of Sox2-deficient embryos, indicating that Cre-mediated excision of Sox2 took place at or before E12.5 in the Vgat-cre;Sox2 $2^{f l f l}$ model. E12.5 corresponds to the onset of mouse SCN neurogenesis, which peaks at E13.5 and concludes at E15 [40]. Notably, VGAT expression is limited to the parenchymal region lateral to the ventricular zone, suggesting that Sox2 was not ablated from hypothalamic progenitor cells lining the third ventricle (Figure 2A,B). This is consistent with the notion that GABAergic fate determination occurs in the post-mitotic period [41]. Collectively, these data show that in the Vgat-cre;Sox $2^{f l f l}$ model, the expression of Sox2 is ablated specifically in post-mitotic cells of the ventral anterior hypothalamus from E12.5 onwards, while its expression in hypothalamic progenitor cells remains intact throughout embryonic development.

\subsection{Reduction of SCN Size Is Caused by Postnatal Cell Loss in Sox2-Deficient SCN}

Given the well-established role of Sox2 in neurogenesis and the timing of Sox2 ablation in our mouse model, we asked whether the reduction in SCN cell numbers and size in adult Sox2 cKO animals may be due to a defective neurogenic program [32-35]. To examine SCN neurogenesis, we injected timed-pregnant $S o x 2^{f l / f l}$ females that had been mated with Vgat-cre;Sox $\mathrm{f}^{f /+}$ males with the thymidine analog, bromodeoxyuridine (BrdU), at either E12.5, E13.5, E14.5, or E15.5 to label proliferating cells in the S-phase. Two hours after the injection, embryos were harvested to determine the number and density of $\mathrm{BrdU}^{+}$cells in the SCN region by immunofluorescence labeling. There was no significant difference in the number or density of BrdU ${ }^{+}$cells between controls $\left(S o x 2^{f l / f l}\right.$ and Sox $2^{f l /+}$ ) and Sox 2 cKO $\mathrm{SCN}$ at E12.5, E13.5, and E14.5, indicating that Sox2 ablation did not affect cell proliferation during most of the neurogenic period (Figure $3 \mathrm{~A}-\mathrm{C}$ ). The number of BrdU $\mathrm{U}^{+}$cells at E15.5 was very low in both control and Sox $2 \mathrm{cKO}$ pups, making it difficult to draw conclusions from any quantitative comparison (Figure $3 \mathrm{~A}$ ). 
Vgat-cre; Rosa26-LSL-EYFP

SOX2

A

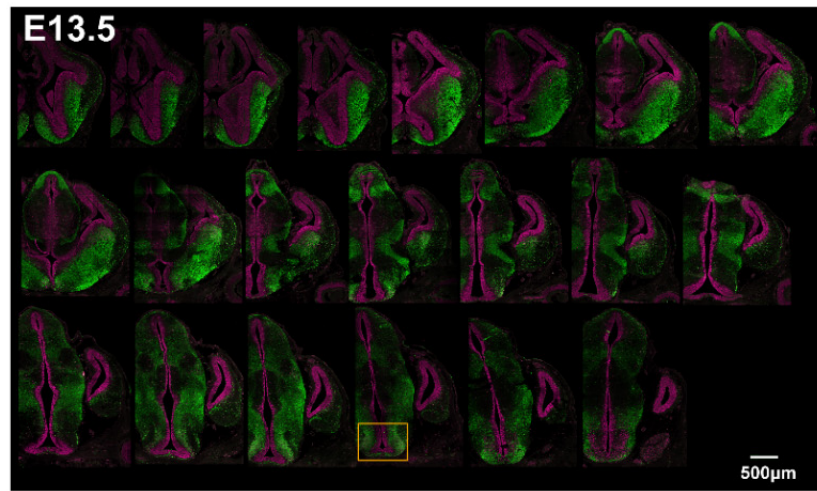

B

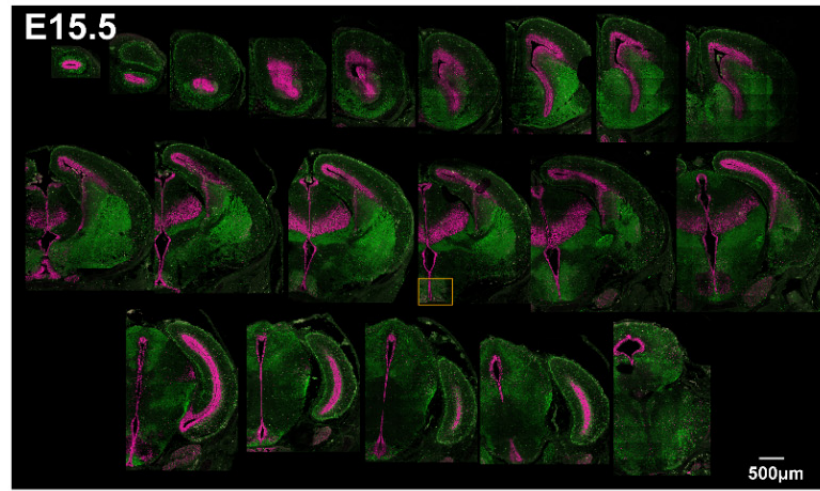

C PO

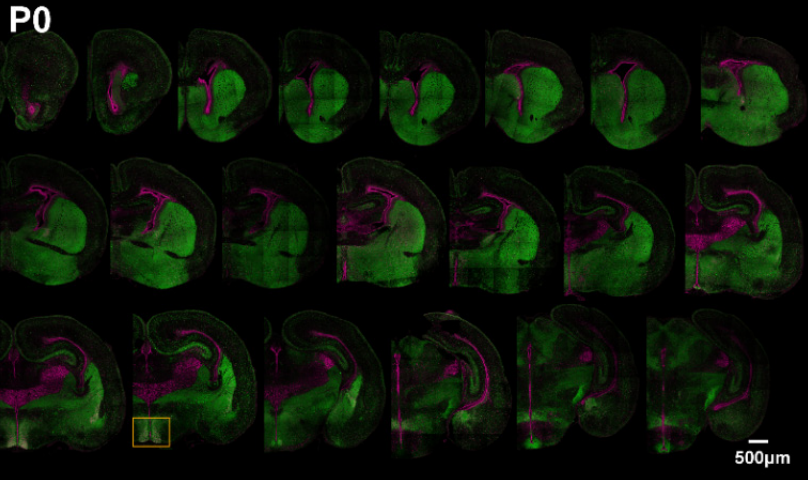

D Adult

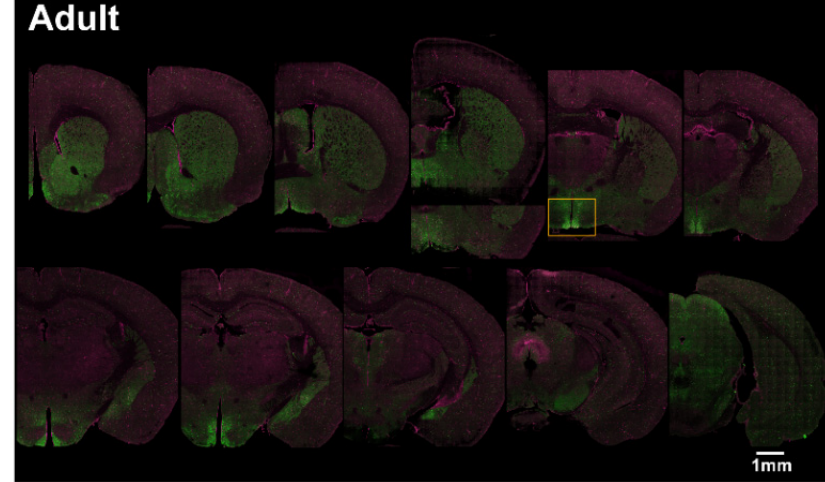

E

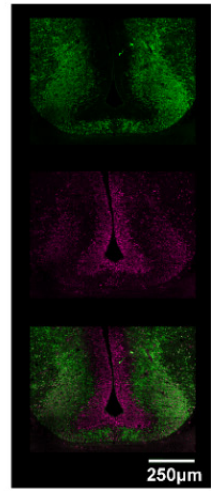

$\mathbf{F}$

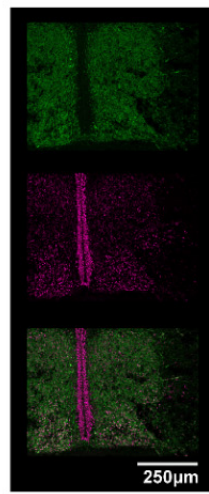

G

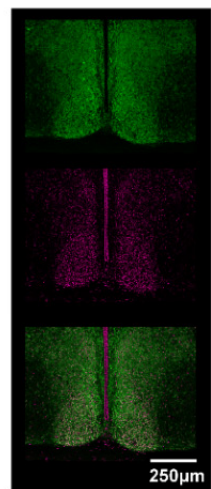

H

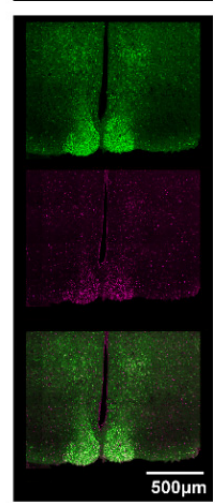

Figure 1. Expression pattern of VGAT and SOX2 in the developing and adult mouse brain. (A-H) Representative photomicrographs of EYFP (proxy for VGAT; green) and SOX2 (magenta) expression in the brains of Vgat-cre;Rosa26-LSL-EYFP mice at (A,E) E13.5, (B,F) E15.5, $(\mathbf{C}, \mathbf{G})$ P0, and $(\mathbf{D}, \mathbf{H})$ the adult stage along the rostral-caudal axis (A-D, from top left to bottom right). Orange rectangles highlight the hypothalamic region containing the developing or mature SCN, which is given in higher magnification in (E-H). 
A

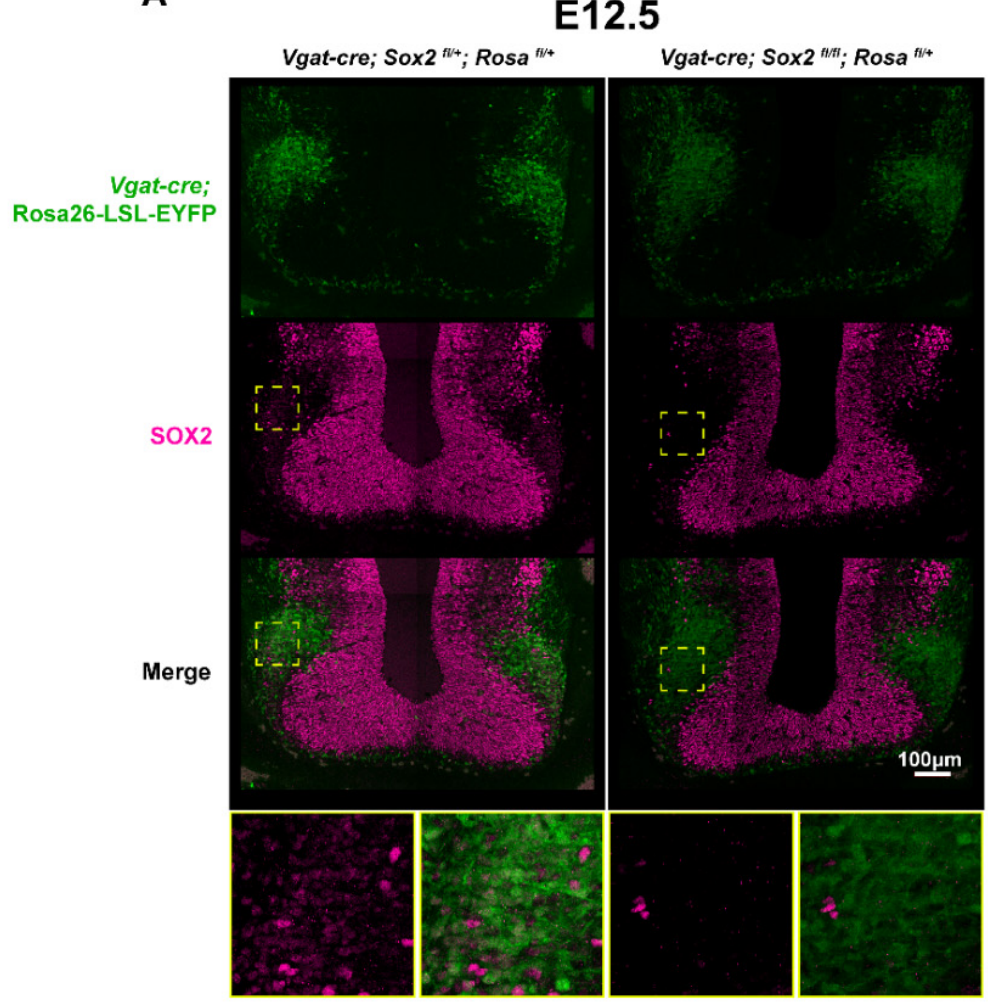

B

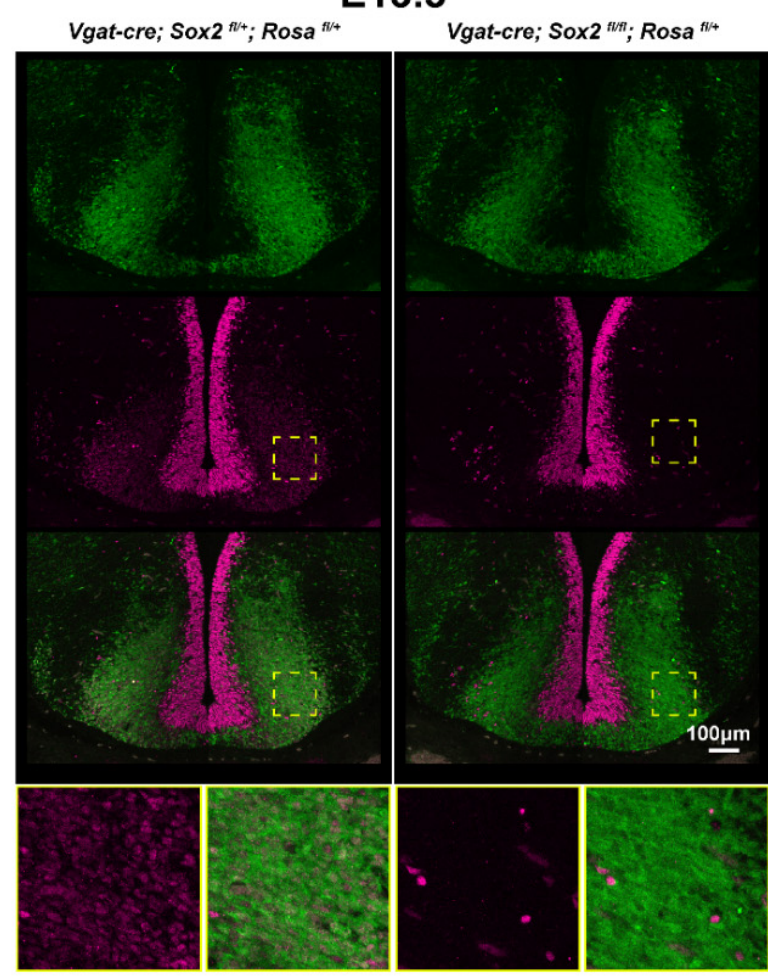

Figure 2. Cre-mediated excision of Sox 2 occurs at or before E12.5 in the Vgat-cre;Sox $2^{\text {fl/fl }}$ model. $(\mathbf{A}, \mathbf{B})$ Expression profile of EYFP (proxy for VGAT, green) and SOX2 (magenta) in the ventral anterior hypothalamus of Sox 2 heterozygous (Vgat-cre;Sox $2^{f l /+}$;Rosa $a^{f l /+}$ ) and Sox $2 \mathrm{cKO}\left(\right.$ Vgat-cre;Sox $2^{f l f l}$;Rosa ${ }^{f l /+}$ ) mice at (A) E12.5 and (B) E13.5. Yellow dotted squares highlight the parenchymal region with colocalized expression of VGAT and SOX2 in control animals, and the corresponding anatomical location in mutants. Higher magnification images of the outlined regions are shown in the bottommost panels. One litter of E12.5 Sox 2 heterozygous $(n=2)$ and Sox $2 \mathrm{cKO}(n=2)$ animals were analyzed. Two litters of E13.5 Sox 2 heterozygous ( $n=1$ from each litter; total $n=2)$ and Sox $2 \mathrm{cKO}(n=1$ from each litter, total $n=2)$ animals were analyzed.

Given the lack of a cell proliferation phenotype, we next examined the impact of Sox 2 ablation on the survival of SCN neurons in the early postnatal stage. Apoptotic cell death in the developing $\mathrm{SCN}$ begins as synapse formation increases, with substantial death occurring between P1 and P7 in mice [28,42,43]. To study cell survival, pregnant Sox $2^{f l / f l}$ dams that had been mated with $\mathrm{Vgat}-\mathrm{cre} ; \mathrm{Sox} 2^{\mathrm{fl} / \mathrm{+}}$ males were given once-daily injections of BrdU during the neurogenic period of E12.5 to E15.5. Pups were collected on P0 and P7 to determine the number and density of BrdU-retaining cells in the SCN before (P0) and after (P7) the peak of SCN cell death. These label-retaining cells, or LRCs, represent the surviving progeny cells of those that were in S-phase at the time of the BrdU injections. There was no significant difference in the number and density of BrdU-retaining cells between P0 Sox2 cKO pups and littermate controls (Sox $2^{f l / f l}$ and $S o x 2^{f l /+}$ pups) (Figure 3D,F,G). However, at P7, the number of BrdU ${ }^{+}$cells in Sox $2 \mathrm{cKO}$ mice was reduced by approximately $24 \%$ compared to controls (Figure 3E-G). The density of BrdU-retaining cells at P7 was similar between Sox2 cKO and control mice, as the mutant $\mathrm{SCN}$ was slightly smaller than the control (Figure 3E-G). Taken together, these results suggest that the reduced number of SCN neurons in adult Sox 2 cKO mice is likely stemming from greater neuronal cell loss in the postnatal period rather than a decrease in cell proliferation during SCN neurogenesis. 
A

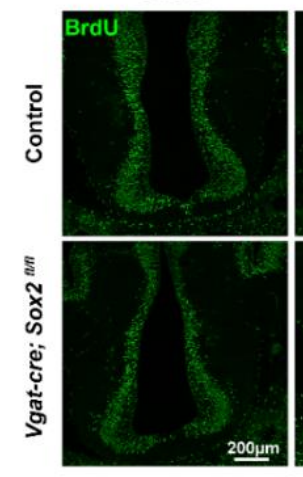

E13.5

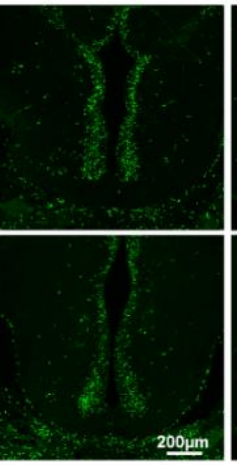

E14.5

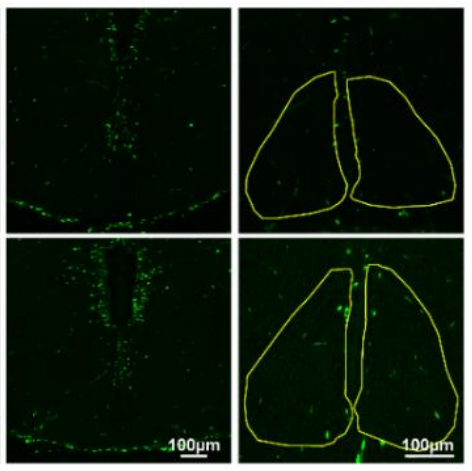

B

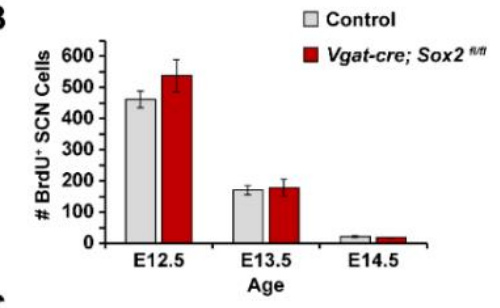

C

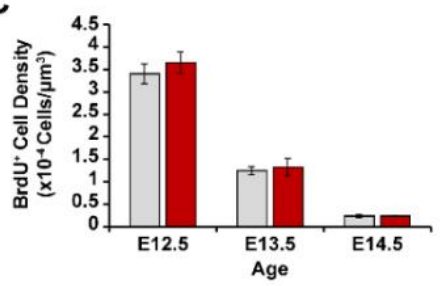

D
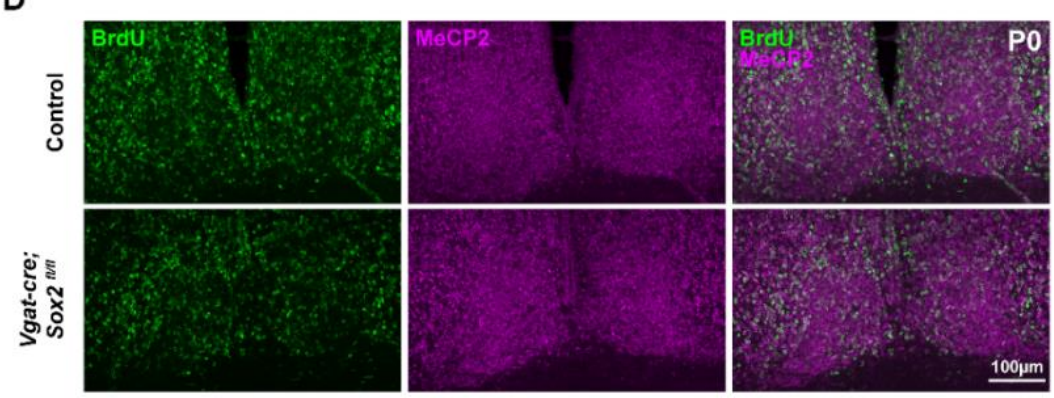

0

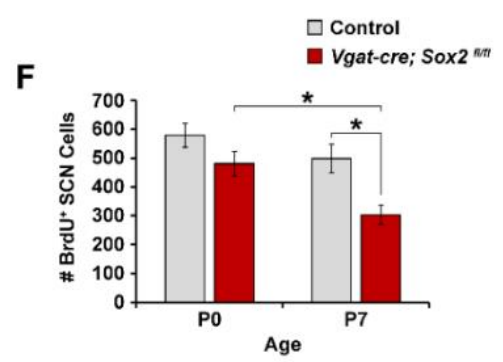

E
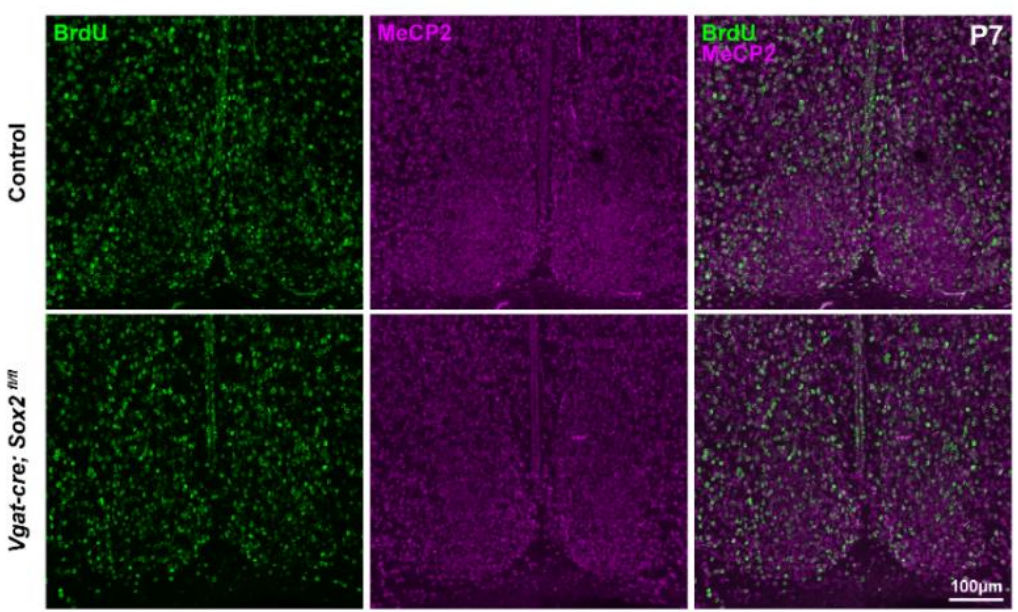

G

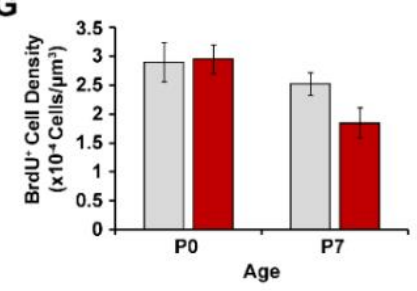

Figure 3. Vgat-cre;Sox $2^{f l / f l}$ mice exhibit normal cell proliferation during SCN neurogenesis, but fewer newborn neurons survive in the postnatal SCN. (A) Representative photomicrographs of BrdU immunoreactivity (green) in the ventral anterior hypothalamus or SCN of control and Vgat-cre;Sox $2^{f l f l}$ mice at E12.5, E13.5, E14.5, and E15.5. (B) Number of BrdU ${ }^{+}$cells in the ventral anterior hypothalamus of control and Sox2 cKO embryos at E12.5, E13.5, and E14.5. (C) Quantification of BrdU ${ }^{+}$cell density in the ventral anterior hypothalamus at E12.5, E13.5, and E14.5. (D,E) Representative photomicrographs of BrdU (green) and MeCP2 (magenta) immunoreactivity in the (D) P0 and (E) P7 SCN of control and Vgat-cre;Sox $2^{f l f l}$ animals that had received daily pulses of BrdU from E12.5 to E15.5. (F,G) Quantification of (F) number and (G) density of BrdU ${ }^{+}$cells in the P0 and P7 SCN. Values represent mean \pm SEM. ${ }^{*} p<0.05$, two-way ANOVA with Tukey HSD. See Table 1 for the number of animals and litters used. 
Table 1. Animals and litters used for BrdU assays and the corresponding representative figure.

\begin{tabular}{|c|c|c|c|c|c|c|}
\hline Exp & Age & Litter & Sox $2^{f l f f l}(n)$ & $\operatorname{Sox} 2^{f l++}(n)$ & Sox 2 cKO (n) & Figure \\
\hline \multirow{3}{*}{1} & \multirow{3}{*}{ E12.5 } & A & 2 & 0 & 1 & \multirow{10}{*}{$3 \mathrm{~A}-\mathrm{C}$} \\
\hline & & B & 2 & 0 & 3 & \\
\hline & & Total & \multicolumn{2}{|c|}{4} & 4 & \\
\hline \multirow{3}{*}{2} & \multirow{3}{*}{ E13.5 } & $\mathrm{A}$ & 1 & 1 & 3 & \\
\hline & & B & 2 & 1 & 3 & \\
\hline & & Total & \multicolumn{2}{|c|}{5} & 6 & \\
\hline \multirow{4}{*}{3} & \multirow{4}{*}{ E14.5 } & $\mathrm{A}$ & 1 & 1 & 3 & \\
\hline & & B & 1 & 1 & 1 & \\
\hline & & $\mathrm{C}$ & 0 & 1 & 2 & \\
\hline & & Total & \multicolumn{2}{|c|}{5} & 6 & \\
\hline \multirow{5}{*}{4} & \multirow{5}{*}{ P0 } & $\mathrm{A}$ & 2 & 0 & 2 & \multirow{11}{*}{$3 \mathrm{D}-\mathrm{G}$} \\
\hline & & B & 0 & 0 & 1 & \\
\hline & & $C$ & 1 & 0 & 1 & \\
\hline & & $\mathrm{D}$ & 1 & 0 & 0 & \\
\hline & & Total & & & 4 & \\
\hline \multirow{6}{*}{5} & \multirow{6}{*}{ P7 } & A & 1 & 0 & 2 & \\
\hline & & B & 0 & 0 & 1 & \\
\hline & & $\mathrm{C}$ & 0 & 0 & 1 & \\
\hline & & $\mathrm{D}$ & 1 & 0 & 1 & \\
\hline & & $\mathrm{E}$ & 2 & 0 & 0 & \\
\hline & & Total & & & 5 & \\
\hline
\end{tabular}

\subsection{Loss of Sox2 Leads to Reduced Expression of Neuropeptides}

Next, we examined when Sox2-deficient SCN neurons acquire the expression of signature neuropeptides as an indicator of their developmental progression. We profiled the expression pattern of Avp and Vip in E15.5 and E17.5 SCN with fluorescence in situ hybridization. Expression of Avp and Vip was low but detectable in control (Sox $2^{f l f l}$ and Sox $2^{f l /+}$ ) SCN at E15.5 (Figure 5A,D). Avp $p^{+}$cells were concentrated in the medial region proximal to the third ventricle (Figure 5A), while the majority of $\mathrm{Vip}^{+}$cells were situated in the lateral SCN (Figure 5D). There was no significant difference in Avp expression intensity between E15.5 Sox2 cKO and control SCN (Figure 5B). However, the density of $\mathrm{Avp}^{+}$cells was decreased by $\sim 80 \%$ in Sox2-deficient SCN at E15.5 compared to control SCN (Figure 5A,C). Sox2 ablation also reduced the expression of Vip and the density of $\mathrm{Vip}^{+}$cells in E15.5 SCN by 50\% and 57\%, respectively (Figure 5D-F). Between E15.5 and E17.5, the density of $\mathrm{Avp}^{+}$and $\mathrm{Vip}^{+}$cells in control SCN increased by 6.25- and 2.4-fold, respectively, as more SCN neurons differentiated and began to express neuropeptides (Figure 5C,F,I,L). A similar phenomenon was observed in Sox2-deficient SCN in the same period, during which the density of $\mathrm{Avp}^{+}$cells and $\mathrm{Vip}^{+}$cells increased by 10- and 2-fold, respectively (Figure 5C,F,I,L). However, at E17.5, Sox2-deficient SCN continued to exhibit significantly lower expression of Avp and Vip and lower density of $\mathrm{Avp}^{+}$and $\mathrm{Vip}^{+}$cells relative to control SCN (Figure 5C,F,I,L). From E17.5 to P0, the density of $\mathrm{Avp}^{+}$cells in control and Sox $2 \mathrm{cKO}$ SCN further increased by 2- and 2.5-fold, respectively (Figures $5 \mathrm{I}$ and $4 \mathrm{C}$ ). Avp ${ }^{+}$cell density was reduced by $\sim 45 \%$ in $\mathrm{P} 0$ Sox2-deficient SCN relative to controls, with the remaining $\mathrm{Avp}^{+}$cells localized to the medial SCN and absent from the lateral SCN (Figure 4A,C). Between E17.5 and P0, there was also an increase of 1.7- and 2.4-fold in the density of $\mathrm{Vip}^{+}$cells in control and Sox2-deficient SCN, respectively (Figures 5L and 4F). Vip ${ }^{+}$cell 
density was reduced by $\sim 47 \%$ in $\mathrm{P} 0$ Sox 2 cKO animals relative to controls, with the compartmentalization of $\mathrm{Vip}^{+}$cells largely resembling that of wild-type animals (Figure 4D,F). In addition to Avp and Vip, we characterized the expression profile of three other SCN neuropeptides, Grp, Nms, and Prok2, in P0 control and Sox2-deficient SCN. The levels of Nms and Prok2, but not Grp, were significantly reduced in Sox 2 cKO SCN compared to controls (Figure 4G-L). Collectively, our findings suggest that the absence of SOX2 in the developing SCN interferes with the ability of SCN neurons to acquire the expression of their signature neuropeptides.

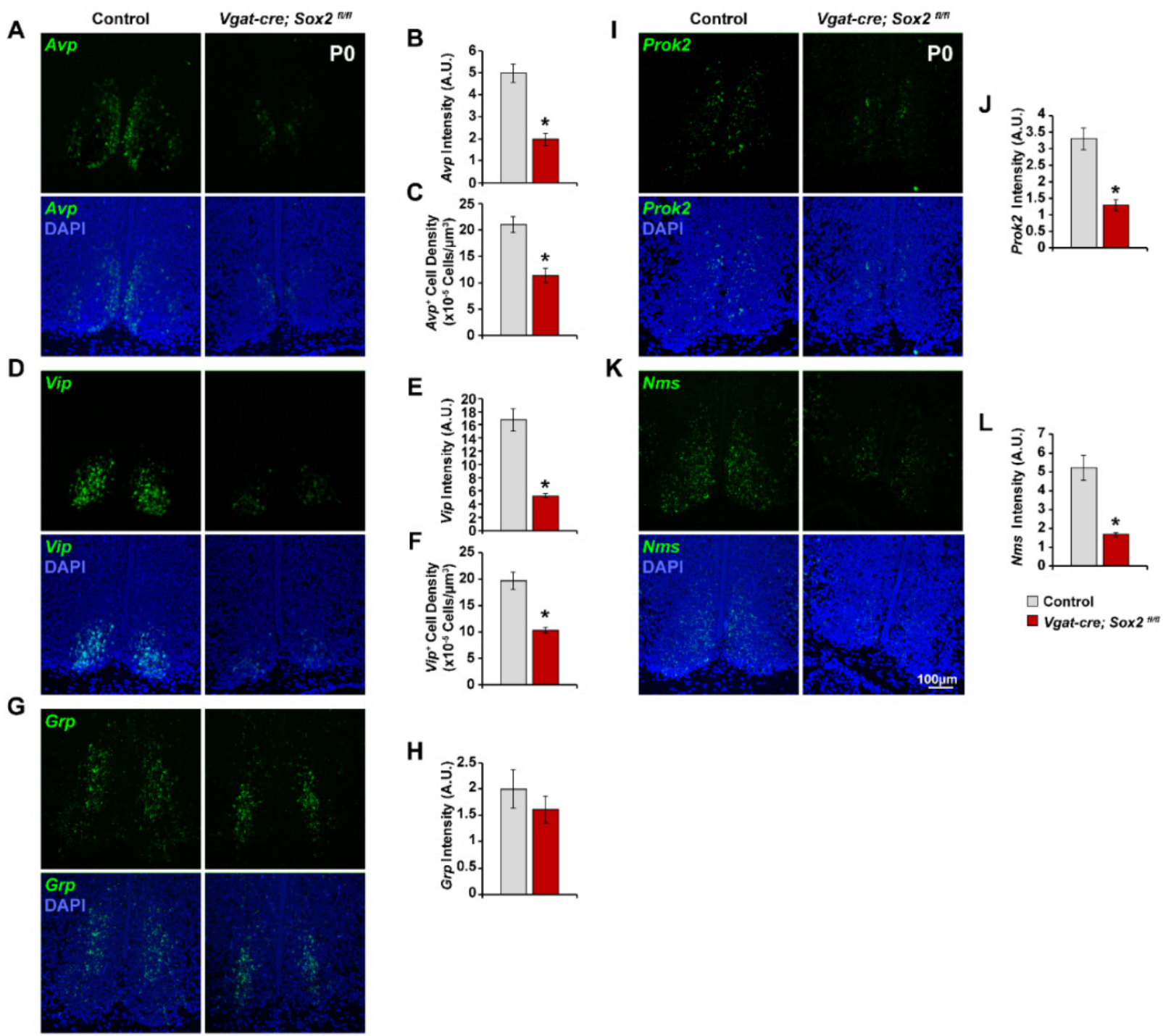

Figure 4. Effects of Sox2 ablation on neuropeptide expression in P0 SCN. (A,D,G,I,K) Representative photomicrographs of (A) Avp, (D) Vip, (G) Grp, (I) Prok2, and (K) Nms expression (green) in the SCN of P0 control and Vgat-cre;Sox $2^{f l f l}$ mutant mice. Blue denotes DAPI. (B,E,H,J,L) Expression of (B) Avp, (E) Vip, (H) Grp, (J) Prok2, and (L) Nms at P0 are quantified in arbitrary units of mean grayscale intensity in the whole SCN. (C,F) Quantification of (C) Avp ${ }^{+}$and (F) Vip ${ }^{+}$cell density in the P0 SCN. Values represent mean \pm SEM. ${ }^{*} p<0.05$ versus control mice, two-tailed Student's $t$-test. See Table 2 for the number of animals and litters used. 


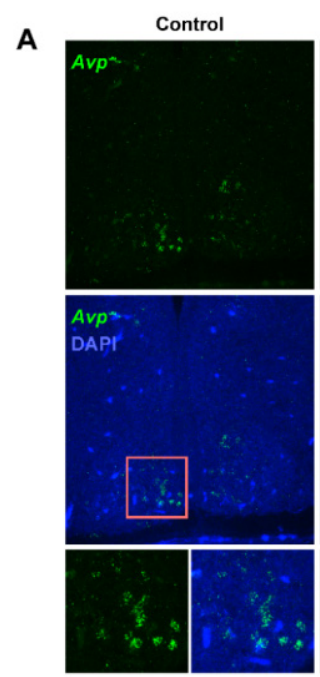

B

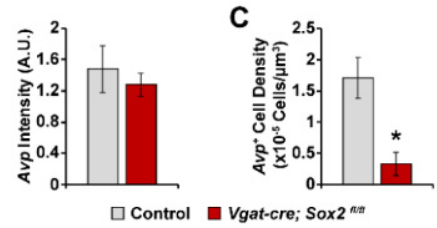

D

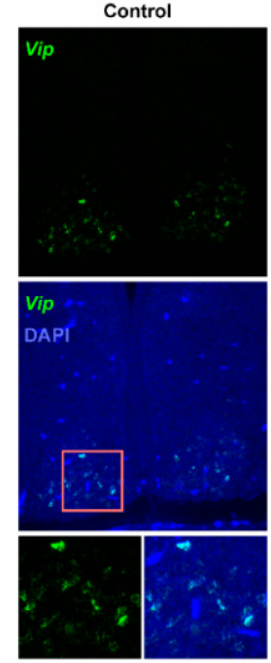

E

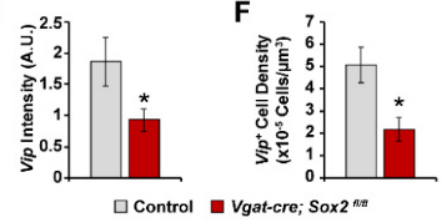

Vgat-cre; Sox2 ${ }^{\mathrm{m}}$

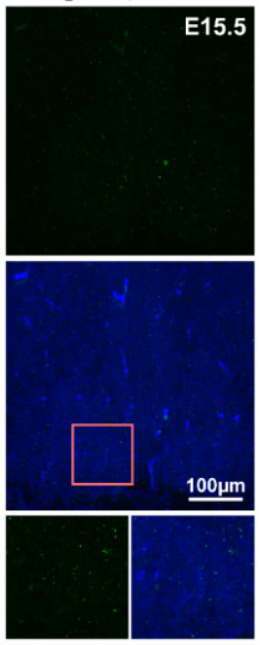

Vgat-cre; Sox $2^{\text {mn }}$

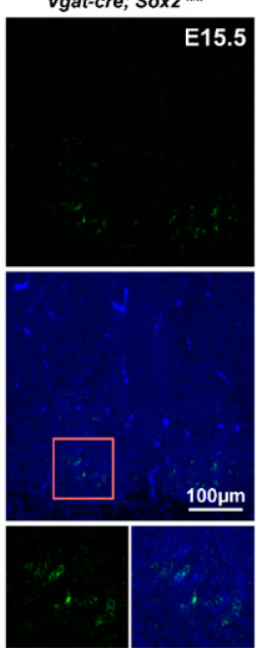

G

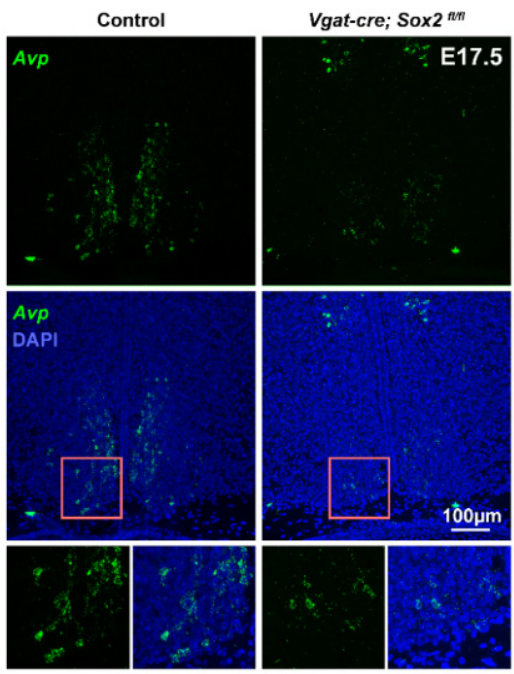

H

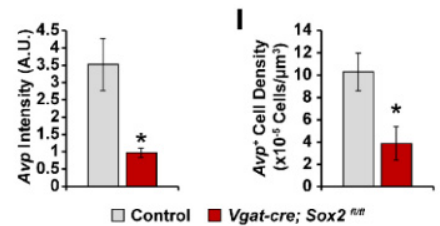

J

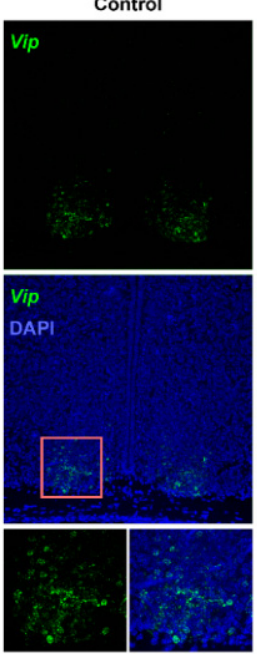

K

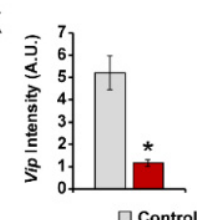

Vgat-cre; Sox ${ }^{n+t}$

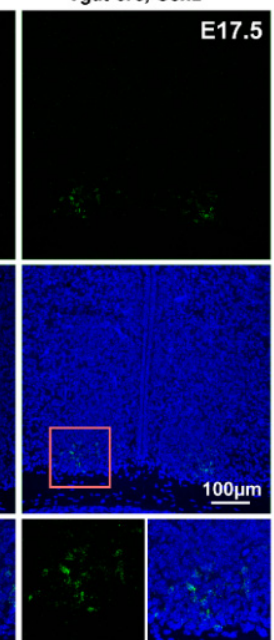

L

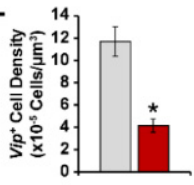

Figure 5. SCN-specific Sox2 ablation suppresses Avp and Vip expression at E15.5 and E17.5. (A,G) Representative photomicrographs of Avp expression (green) in the SCN of (A) E15.5 and (G) E17.5 control and Vgat-cre;Sox2 $2^{f l f l}$ mutant mice. Blue denotes DAPI. (B,H) Quantification of Avp expression in arbitrary units of mean grayscale intensity in the whole SCN at (B) E15.5 and (H) E17.5. (C,I) Quantification of $\mathrm{Avp}^{+}$cell density in the (C) E15.5 and (I) E17.5 SCN. (D,J) Representative photomicrographs of Vip expression (green) in the SCN of (D) E15.5 and (J) E17.5 control and Vgat-cre;Sox $2^{\text {fl/fl }}$ mutant mice. Blue denotes DAPI. (E, K) Quantification of Vip expression in arbitrary units of mean grayscale intensity in the whole SCN at (E) E15.5 and (K) E17.5. (F,L) Quantification of Vip ${ }^{+}$cell density in the (F) E15.5 and (L) E17.5 SCN. Values represent mean \pm SEM. ${ }^{*} p<0.05$ versus control mice, two-tailed Student's $t$-test. See Table 2 for the number of animals and litters used. 
Table 2. Animals, litters, RNAscope probes used and the corresponding representative figures.

\begin{tabular}{|c|c|c|c|c|c|c|}
\hline \multirow{2}{*}{ Exp. } & \multirow{2}{*}{ Age } & \multirow{2}{*}{ RNAscope Probe (Identifier) } & \multirow{2}{*}{ Figure } & Sox $2^{f l f l}$ & $\operatorname{Sox} 2^{f l+}$ & Sox $2 \mathrm{cKO}$ \\
\hline & & & & \multicolumn{3}{|c|}{$($ Litter-n) } \\
\hline \multirow{2}{*}{1} & \multirow{2}{*}{ E12.5 } & Lhx1 (488581) & $6 \mathrm{~A}$ & \multirow{2}{*}{$\begin{array}{l}\mathrm{A}-2 ; \\
\mathrm{B}-2\end{array}$} & \multirow{2}{*}{$\begin{array}{l}\mathrm{A}-0 ; \\
\mathrm{B}-0\end{array}$} & \multirow{2}{*}{$\begin{array}{l}\text { A-1; } \\
\text { B-3 }\end{array}$} \\
\hline & & $\operatorname{Rax}(528561-\mathrm{C} 2)$ & $6 \mathrm{~A}$ & & & \\
\hline \multirow{3}{*}{2} & \multirow{3}{*}{ E14.5 } & Six6 (574291) & $6 \mathrm{~F}$ & \multirow{3}{*}{$\begin{array}{l}\text { A-1; } \\
\text { B-1; } \\
\text { C-0 }\end{array}$} & \multirow{3}{*}{$\begin{array}{l}\mathrm{A}-1 ; \\
\mathrm{B}-1 ; \\
\mathrm{C}-1\end{array}$} & \multirow{3}{*}{$\begin{array}{l}\mathrm{A}-3 ; \\
\mathrm{B}-1 ; \\
\mathrm{C}-2\end{array}$} \\
\hline & & Lhx1 (488581-C2) & $6 \mathrm{~B}$ & & & \\
\hline & & Six3 (412941-C3) & $6 \mathrm{D}$ & & & \\
\hline \multirow{3}{*}{3} & \multirow{3}{*}{ E15.5 } & Lhx1 (488581) & $6 \mathrm{H}$ & \multirow{3}{*}{$\begin{array}{l}\mathrm{A}-1 ; \\
\mathrm{B}-1 ; \\
\mathrm{C}-1 ; \\
\mathrm{D}-1\end{array}$} & \multirow{3}{*}{$\begin{array}{l}\mathrm{A}-0 ; \\
\mathrm{B}-0 ; \\
\mathrm{C}-0 ; \\
\mathrm{D}-0\end{array}$} & \multirow{3}{*}{$\begin{array}{l}\mathrm{A}-1 ; \\
\mathrm{B}-1 ; \\
\mathrm{C}-1 ; \\
\mathrm{D}-1\end{array}$} \\
\hline & & Avp (401391-C2) & $4 \mathrm{~A}$ & & & \\
\hline & & Vip (415961-C3) & $4 \mathrm{D}$ & & & \\
\hline \multirow{2}{*}{4} & \multirow{2}{*}{ E15.5 } & Six6 (574291) & $6 \mathrm{~L}$ & \multirow{2}{*}{$\begin{array}{l}\mathrm{A}-3 ; \\
\mathrm{B}-1 ; \\
\mathrm{C}-1\end{array}$} & \multirow{2}{*}{$\begin{array}{l}\mathrm{A}-0 ; \\
\mathrm{B}-0 ; \\
\mathrm{C}-0\end{array}$} & \multirow{2}{*}{$\begin{array}{l}\mathrm{A}-2 ; \\
\mathrm{B}-1 ; \\
\mathrm{C}-1\end{array}$} \\
\hline & & Six3 (412941-C3) & $6 \mathrm{~J}$ & & & \\
\hline \multirow{3}{*}{5} & \multirow{3}{*}{ E17.5 } & Six6 (574291) & $6 \mathrm{P}$ & \multirow{4}{*}{$\begin{array}{l}\mathrm{A}-1 \\
\mathrm{~B}-3\end{array}$} & \multirow{4}{*}{$\begin{array}{l}\mathrm{A}-1 ; \\
\mathrm{B}-0\end{array}$} & \multirow{4}{*}{$\begin{array}{l}\mathrm{A}-2 ; \\
\mathrm{B}-2\end{array}$} \\
\hline & & $\operatorname{Lh} x 1$ (488581-C2) & $6 \mathrm{~N}$ & & & \\
\hline & & Avp (401391-C3) & $4 \mathrm{G}^{*}$ & & & \\
\hline 6 & E17.5 & Vip (415961-C3) & $4 \mathrm{~J}$ & & & \\
\hline 7 & P0 & Grp (317861) & $5 \mathrm{G}$ & & & \\
\hline \multirow{2}{*}{12} & \multirow{2}{*}{ P0 } & Six6 (574291) & $7 \mathrm{E}$ & $\begin{array}{c}\mathrm{A}-3 \\
\mathrm{~B}-1\end{array}$ & $\begin{array}{l}\mathrm{A}-0 ; \\
\mathrm{B}-0\end{array}$ & $\begin{array}{l}\mathrm{A}-3 ; \\
\mathrm{B}-1\end{array}$ \\
\hline & & $\operatorname{Vax} 1$ (805101-C2) & $7 \mathrm{~K}$ & & & \\
\hline 8 & P0 & Prok2 (447941) & $5 \mathrm{I}$ & A-1; & A-0; & A-1; \\
\hline 9 & P0 & Nms (472331) & $5 \mathrm{~K}$ & $\begin{array}{l}\mathrm{B}-1 ; \\
\mathrm{C}-2\end{array}$ & $\begin{array}{l}\mathrm{B}-1 ; \\
\mathrm{C}-0\end{array}$ & $\begin{array}{l}B-2 ; \\
C-3\end{array}$ \\
\hline & & Lhx1 (488581) & $7 \mathrm{~A}$ & A-1; & $\mathrm{A}-0$ & A-1; \\
\hline 10 & P0 & Avp (401391-C2) & $5 \mathrm{~A}$ & $\begin{array}{l}\text { B-1; } \\
\text { C-1: }\end{array}$ & $\begin{array}{l}\text { B-0; } \\
\text { C- } 0\end{array}$ & $\begin{array}{l}\text { B-1; } \\
\text { C-1: }\end{array}$ \\
\hline & & Vip (415961-C3) & $5 \mathrm{D}$ & $\mathrm{D}-1$ & $\mathrm{D}-0$ & $\mathrm{D}-1$ \\
\hline & & Rora (520031) & $7 \mathrm{G}$ & & & \\
\hline 11 & P0 & Rorb (444271-C2) & $7 \mathrm{I}$ & $\mathrm{B}-0$; & $\mathrm{B}-0$ & B-1; \\
\hline & & Six3 (412941-C3) & $7 \mathrm{C}$ & $C-2$ & $\mathrm{C}-0$ & $\mathrm{C}-1$ \\
\hline
\end{tabular}

${ }^{*}$ A different control is shown as the representative photomicrograph.

2.4. Ablation of SOX2 in SCN Neurons Impairs Lhx1 and Six6 Expression at Birth but Not during Embryonic Development

The SCN expresses many transcription factors at different developmental stages, and a small subset of these genetic markers has been confirmed to regulate SCN specification and terminal differentiation $[23,25,28]$. To address the possibility that Sox2 may be modulating SCN development by controlling the expression of known transcription factors, we characterized the expression of three major SCN specification and differentiation factors, Lhx1, Six3, and Six6, in the developing SCN of Sox2 cKO and control (Sox $2^{f l / f l}$ and Sox $2^{f l /+}$ ) mice. There was no significant difference in the expression of the SCN differentiation factor, Lhx1, at E14.5, E15.5, and E17.5 (Figure 6B,C,H,I,N,O). The level and distribution of Lhx1 expression appeared to be similar between Sox $2 \mathrm{cKO}$ and control SCN at E12.5, which was also the case for Rax, a transcription factor that is expressed in the early neuroepithelium (Figure 6A). The expression of the SCN specification factor, Six6, in Sox2-deficient SCN was intact at E14.5, E15.5, and E17.5, consistent with the preservation of a histologically recognizable SCN in our mutant mice (Figure 6F,G,L,M,P,Q; [23]). Sox2 ablation did not affect the expression of another early specification marker of the SCN, Six3, at either E14.5 or E15.5 (Figure 6D,G,J,K; [25]). However, expression of Lhx1 and Six6, but not Six3, was eventually disrupted by Sox2 ablation at P0: Lhx1 and Six 6 were significantly attenuated in the dorsomedial SCN of Sox $2 \mathrm{cKO}$ mice, mirroring the phenotype seen in the adults (Figure 7A,B,E,F) [37,38]. 

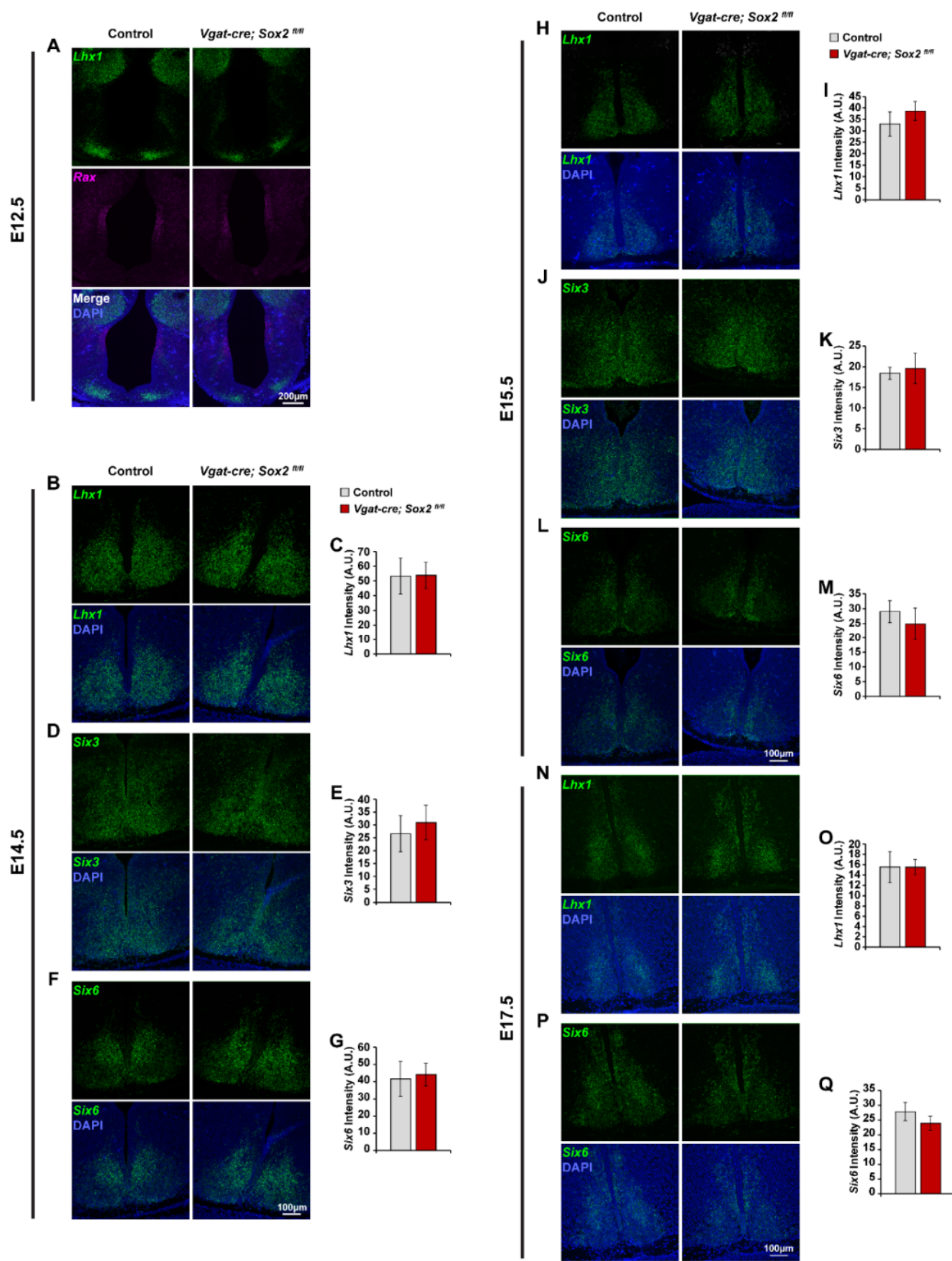

Figure 6. The expression of major SCN-enriched transcription factors is preserved in the embryonic, Sox2-deficient SCN. (A) Representative photomicrographs of Lhx1 (green) and Rax (magenta) expression in the anterior hypothalamus of E12.5 control and Vgat-cre;Sox $2^{f l f l}$ mutant embryos. Blue denotes DAPI. (B,D,F) Representative photomicrographs of (B) Lhx1, (D) Six3, and (F) Six6 expression (green) in the E14.5 SCN of control and Vgat-cre;Sox $2^{f l / f l}$ mutant embryos. Blue denotes DAPI. (C,E,G) The expression of (C) Lhx1, (E) Six3, and (G) Six6 at E14.5 are quantified in arbitrary units of mean grayscale intensity in the whole SCN. $(\mathbf{H}, \mathbf{J}, \mathbf{L})$ Representative photomicrographs of $(\mathbf{H})$ Lhx1, (J) Six3, and (L) Six 6 expression (green) in the E15.5 SCN of control and Vgat-cre;Sox $2^{\text {flffl }}$ mutant embryos. Blue denotes DAPI. (I,K,M) The expression of (I) Lhx1, (K) Six3, and (M) Six6 at E15.5 are quantified in arbitrary units of mean grayscale intensity in the whole SCN. (N, P) Representative photomicrographs of (N) Lhx1 and (P) Six6 expression (green) in the E17.5 SCN of control and Vgat-cre;Sox $2^{\text {flfl }}$ mutant embryos. Blue denotes DAPI. $(\mathbf{O}, \mathbf{Q})$ The expression of $(\mathbf{O})$ Lhx1 and $(\mathbf{Q})$ Six6 at E17.5 are quantified in arbitrary units of mean grayscale intensity in the whole SCN. Values represent mean \pm SEM. * $p<0.05$ versus control mice, two-tailed Student's $t$-test. See Table 2 for the number of animals and litters used. 


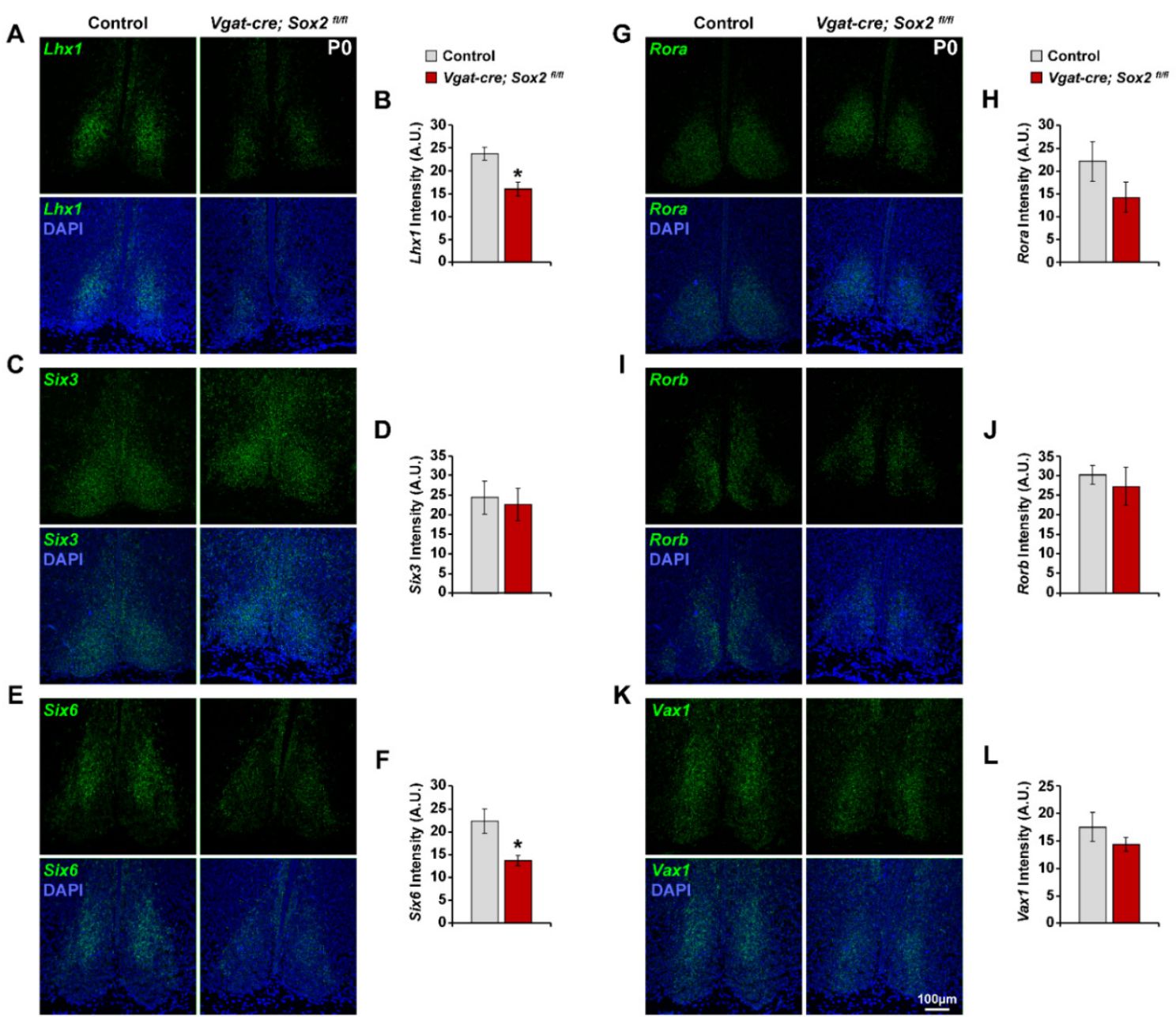

Figure 7. Loss of SOX2 disrupts Lhx1 and Six6 expression in P0 Vgat-cre;Sox $2^{f l f l}$ SCN. (A,C,E,G,I,K) Representative photomicrographs of (A) Lhx1, (C) Six3, (E) Six6, (G) Rora, (I) Rorb, and (K) Vax1 expression (green) in the SCN of P0 control and Vgat-cre;Sox $2^{f l f l}$ mutant mice. Blue denotes DAPI. (B,D,F,H,J,L) The expression of (B) Lhx1, (D) Six3, (F) Six6, (H) Rora, (J) Rorb, and (L) Vax1 at P0 are quantified in arbitrary units of mean grayscale intensity in the whole SCN. Values represent mean \pm SEM. ${ }^{*} p<0.05$ versus control mice, two-tailed Student's $t$-test. See Table 2 for the number of animals and litters used.

To confirm that the downregulation of $\operatorname{Lhx} 1$, Six6, and various neuropeptides in the SCN was not the result of a failure in SCN compartmentalization, we examined the expression of the dorsomedial SCN-specific marker, Rorb, in P0 animals. Rorb retained its normal compartmentalization and intensity when Sox 2 was ablated (Figure 7I,J). We also assessed the expression of two other selective SCN markers, Rora and Vax1. Rora and Vax1 exhibited a largely normal expression profile with no significant difference in signal intensity between Sox2-deficient and control SCN (Figure 7G,H,K,L). In summary, the data suggest that Sox2 deficiency in the SCN downregulates the expression of Lhx1 and Six6 at $\mathrm{P} 0$, but not during embryogenesis when neuronal specification normally takes place.

\section{Discussion}

Our initial characterization of $V g a t-c r e ; S o x 2^{f l f l}$ mice revealed imprecise, poorly consolidated behavioral rhythms that entrained inefficiently to light, but also a visibly smaller SCN compared to control mice [37]. The latter observation raised the possibility that Vgatdriven Sox2 ablation may negatively influence the development of the SCN. Here, we report that SOX2 and VGAT expression colocalize in the developing SCN at E12.5, and 
that Cre-mediated gene excision begins during early SCN neurogenesis. Despite the early excision of Sox2 from GABAergic cells, Vgat-cre;Sox $2^{f l f l}$ mice exhibit normal SCN neurogenesis comparable to littermate controls. The reduction in SCN size is the consequence of enhanced cell loss in the postnatal SCN of Sox2-deficient mice rather than a decrease in cell proliferation during embryogenesis. In the absence of SOX2, the expression of several SCN-enriched neuropeptides including Avp, Vip, Prok2, and Nms is markedly diminished, some as early as E15.5. This suggests that Sox2 ablation may impede the differentiation of neuropeptidergic neurons, potentially contributing to the circadian phenotype of adult Vgat-cre;Sox $2^{f l f l}$ mice.

Using a Cre-reporter mouse strain, we confirmed that SCN-specific Sox2 ablation in the Vgat-cre;Sox $2^{f l f l}$ mouse model occurs on or before E12.5. Notably, SOX2 is concentrated at the neuroepithelium lining the third ventricle, while EYFP, a proxy for Cre and Vgat expression, has moderate colocalization with SOX2 in the ventral anterior hypothalamus beginning at E12.5. More SOX2 ${ }^{+} \mathrm{EYFP}^{+}$cells are present in the parenchymal region lateral to the third ventricle at E13.5, and Vgat-driven expression of Cre essentially ablates SOX2 from this population of cells, which will eventually form the SCN. Neuroepithelial expression of SOX2 is intact throughout development as Vgat is not expressed in this region. At later timepoints, colocalized expression of SOX2 and EYFP remains confined to the SCN and is virtually undetected in other brain regions including other hypothalamic nuclei.

SOX2 is a neuronal stem/progenitor cell marker that labels mitotic cells in neurogenic niches during embryonic and adult neurogenesis. On the other hand, Vgat is considered to be a marker of terminally differentiated cells: it is expressed in postmitotic, GABAergic neurons and confers cell type-specific functional properties [41]. Using Vgat to drive Sox2 excision essentially protects proliferating progenitors as well as early postmitotic, nonGABAergic precursors from Sox 2 deletion. The mutually exclusive nature of $V g a t$ and Sox 2 expression in major neurogenic niches also allows for normal genesis of the nervous system in $V g a t$-driven Sox $2 \mathrm{cKO}$ animals and prevents the major deficiencies observed in constitutive, Foxg1- or Nestin-driven Sox2 KO mouse models [32-36]. Furthermore, Sox2 is usually suppressed when proliferating progenitors are triggered to exit the cell cycle by proneural genes. However, this does not apply to SCN neurons, as their expression of Sox2 is retained throughout differentiation and maturation, rendering them susceptible to the effects of $V g a t$-driven Sox 2 deletion. Indeed, the $V g a t$-cre;Sox $2^{f l / f l}$ model provides a unique intersectional approach to delineate the function of Sox2 in SCN development independent of its role in pluripotency or the proliferation of most neural progenitors.

By labeling S-phase cells with a thymidine analog, we found that cell proliferation during the window of SCN neurogenesis is not affected by Sox2 deletion. These data suggest that the reduced SCN volume observed in adult Sox $2 \mathrm{cKO}$ mice is unlikely to be the consequence of a proliferation defect in SCN neuronal precursors. They are also consistent with the observation that Vgat-driven Sox 2 ablation does not perturb the expression of SOX2 in proliferating hypothalamic progenitors lining the third ventricle as recombination occurs only in post-mitotic cells. In contrast, the BrdU retention experiment revealed that significantly fewer of these previously dividing cells survive to P7 in the absence of SOX2, accounting for the reduction in SCN volume.

Cheng et al. (2019a) established that Sox2 deletion dramatically downregulates the expression of neuropeptides, neuropeptide receptors, and core clock genes in adult mice, causing disrupted circadian clock function [37]. Transcription factors with critical developmental roles, such as $\operatorname{Lhx} 1$ and Six6, are also differentially expressed in Sox2-deficient, adult SCN. This prompted us to consider potential defects in terminal differentiation or early SCN specification, akin to the phenotypes elicited by ventral anterior hypothalamusspecific deletion of $L h x 1$ and constitutive deletion of Six6, respectively [23,28]. Our ISH results showed that the SCN of Sox2-deficient P0 mice already exhibit drastically lower expression of Avp, Vip, Lhx1, and Six6, suggesting that Sox2 ablation is detrimental to SCN development. This observation gave rise to three non-mutually exclusive hypotheses that could explain the developmental defects in Sox2 cKO mice. First, SOX2 might 
regulate Six6 expression: Sox2 ablation would disrupt the Six6 transcriptional program leading to a partial failure of SCN specification and patterning, and ultimately the loss of Lhx1-mediated SCN terminal differentiation. Second, Sox 2 might regulate Lhx1 expression independently of Six6: deleting Sox2 would lead to a downregulation of Lhx1 and the subsequent loss of neuropeptidergic neuronal populations. In support of these hypotheses, in silico analyses reported in Cheng et al. (2019b) suggested that SOX2 might directly regulate Six 6 and $L h x 1$ expression in the SCN [38]. Third, differentiation and maturation of SCN neurons could be regulated by Sox 2 either directly or through uncharacterized pathways that operate independently of $\operatorname{Lhx} 1$ and Six6. To determine the validity of these hypotheses, we examined the expression of Avp, Vip, Lhx1, and Six6 in the SCN at E14.5, E15.5, and E17.5. We found that the numbers of $A v p^{+}$and $V_{i p}{ }^{+}$cells are drastically reduced in the SCN of E15.5 and E17.5 Sox 2 CKO mice, while the expression of Lhx1 and Six6 is unaffected at all embryonic time points. The results suggest that deficits in differentiation of $\mathrm{Avp}^{+}$and $\mathrm{Vip}^{+}$neurons arising from Sox 2 ablation precede, and thus do not require, the downregulation of $\operatorname{Lh} x 1$ and Six 6 , consistent with our third hypothesis. It is plausible that reduced expression of $L h x 1$ and Six 6 at later developmental stages further exacerbates the differentiation phenotype or affects neuronal maturation, but this remains a provisional explanation. Moreover, it is unclear whether SOX2 can directly regulate the transcription of SCN-enriched neuropeptides given the lack of consensus SOX2 binding sites in their gene promoters or enhancer regions [44]. However, more empirical data is required to rule out this possibility.

It is worth noting that cell attrition is not the primary cause for neuropeptide and transcription factor downregulation, as many of these genes already exhibit reduced expression in Sox2-deficient SCN during gestation (Avp and Vip) or at P0 (Prok2, Nms, Lhx1, and Six6), prior to significant neuronal loss. Rather, our data suggest that increased cell death is likely secondary to defects in SCN terminal differentiation in Sox 2 cKO mice, where incompletely differentiated or functionally impaired neurons are cleared by programmed cell death. In support of our hypothesis, direct neuronal reprogramming studies have shown that cells which fail to convert successfully to neurons will instead succumb to cell death [45]. A more detailed characterization of SCN cell death in Sox2-deficient mice should be conducted to determine the underlying mechanism.

Discrepancies with the published literature on the onset and distribution of key clock components are noted. Onsets of Avp and Vip expression have been described to take place at the late embryonic stage ( E18) in mice. However, we were able to detect clear mRNA signals of both neuropeptides as early as E15.5, which is 2.5 days earlier than previously reported in mice and other rodents [25,46-48]. One possible explanation for our earlier detection may be the greater sensitivity of the RNAscope technology compared to traditional ISH methods [49,50]. An alternative, but less likely, explanation is that animals with a Sox $2^{f l f l}$ background have an earlier neuropeptide expression. In terms of $\operatorname{Lh} x 1$ expression, VanDunk et al. (2011) described a dynamic expression pattern throughout the development of the SCN [25]. In that study, Lhx1 is first detected in the anterior hypothalamus at E11.5, gradually spans the entire SCN by E15.5, and then appears to be confined to the medial SCN from E17.5 onwards [25]. In contrast, Bedont et al. (2014) reported that $L h x 1$ expression spans the entire SCN throughout development and after birth [28]. Our results agree with both studies with respect to the onset of $L h x 1$ expression, but align specifically with the findings of Bedont et al. (2014) in terms of the broad distribution of $L h x 1$ throughout the SCN from E14.5 to P0 [28].

Our study reveals that the ablation of Sox 2 during early SCN development disrupts Avp and Vip expression in the embryonic SCN prior to downregulation of Lhx1 and Six6. The ablation of Sox2 likely disrupts differentiation and maturation of neuropeptidergic neurons in the SCN in a Six6- and Lhx1-independent manner, ultimately compromising their ability to survive during the postnatal cell clearance window. These results suggest that some of the phenotypes observed in adult Sox 2 cKO mice may stem from developmental deficits $[37,51]$. Downregulated neuropeptide expression in the adult mutant SCN could 
be explained by immature SCN neurons that fail to differentiate. Although we have only examined the developmental trajectory of the two major populations of peptidergic neurons in Sox2-deficient SCN, other populations including $\mathrm{Nms}^{+}$and $\mathrm{Prok}_{2}^{+}$neurons may have similar impairments in differentiation that account for the diminished expression of their neuropeptides in the adult SCN. This does not preclude the possibility that SOX2 may regulate the transcription of these neuropeptide-encoding genes, either directly or indirectly, beyond the developmental stage. Given the importance of neuropeptides in the communication between SCN neurons and to efferent targets, the behavioral phenotypes of Sox $2 \mathrm{cKO}$ mice that are associated with disrupted intercellular signaling may be partially attributed to abnormal SCN differentiation [37]. For example, a defect in the differentiation of peptidergic populations within the SCN that signal to other brain regions regulating affective behavior may underlie the anxio-depressive-like phenotypes exhibited by Sox 2 cKO mice [51]. In addition to reduced neuropeptide expression, enhanced cell loss results in a smaller SCN network, which would likely impact clock network dynamics and stability in Sox2-deficient SCN; however, further experiments are needed to establish the specific effects of a smaller oscillator. It is also not clear whether altered intra-SCN communication is responsible for the blunted expression of several core clock genes, including Arntl, Cry1, Per2, and Rora, in the SCN of adult Sox 2 cKO mice. We do not believe this to be the case, as these clock genes are downregulated at only one (or, in the case of Arntl, two) time point(s), and the magnitude of their downregulation is less striking compared to that of differentially expressed neuropeptides and their receptors $[37,38]$. Overall, our study positions Sox 2 as a novel differentiation factor within the SCN that is required for the development of major peptidergic populations.

\section{Materials and Methods}

\subsection{Animals}

All animal handling and experimental procedures were performed at the University of Toronto Mississauga (UTM) Animal Facility and were approved by the UTM Animal Care Committee, complying with guidelines established by the University of Toronto Animal Care Committee and the Canadian Council on Animal Care. The following mouse strains were purchased from The Jackson Laboratory (Bar Harbor, ME, USA) and bred in-house to generate the appropriate genotypes for this study: homozygous Sox $2^{f l / f l}$ mice in which the coding exon of Sox2 is flanked by loxP sequences (Sox $2^{\text {tm1.1Lan }}$; homozygous VgatIRES-Cre $\left(\right.$ Vgat $\left.^{\text {cre/cre }}\right)$ knock-in mice in which the IRES-Cre recombinase cassette is inserted downstream of the stop codon of the endogenous vesicular GABA transporter (Vgat) gene $\left(S l c 32 a 1^{\text {tm2(cre)Lowl }) ; ~ a n d ~ h o m o z y g o u s ~ R o s a 26-l o x P-S T O P-l o x P-E Y F P ~(R o s a f l f l ~}\right)$ mice in which EYFP expression is induced by Cre/loxP-mediated excision of an upstream STOP sequence (Gt(ROSA)26Sor $\left.{ }^{t m 1(E Y F P) C o s}\right)$. Vgat ${ }^{\text {cre/cre }}$ mice were bred to Sox $2^{\text {fl/fl }}$ mice, and a breeding colony was maintained by mating Sox $2^{\text {fl/fl }}$ mice with $V g a t^{\text {crel++}} ;$ Sox $2^{f l /+}$ mice. Vgat ${ }^{\text {cre/cre }}$ mice were mated with Rosal ${ }^{f l f l}$ animals to generate $\mathrm{Vgat}^{\mathrm{cre} /+} ; \mathrm{Rosa}^{f l /+}$ mice for mapping of VGAT and SOX2 expression. To confirm loss of SOX2 expression, Sox $2^{f l f l f} ;$ Rosa $a^{f l f l}$ mice were bred with $\mathrm{Vgat}^{\text {cre/++}} ;$ Sox $2^{f l /+}$ mice to obtain $\mathrm{Vgat}^{\mathrm{cre} /+}$;Sox $2^{\mathrm{fl} / \mathrm{fl}} ; \mathrm{Rosa}^{\mathrm{fl} /+}$ (Sox2 conditional knockout) and $V g a t^{\text {cre } /+} ;$ Sox $2^{f l /+} ;$ Rosa $a^{f l++}$ (Sox2 heterozygous) animals for analysis. Littermate Sox $2^{f l / f l}$ and Sox $2^{f l /+}$ mice were used as controls for all other experiments. Mice were bred and maintained on a fixed 12-hr light:12-hr dark (12:12 LD) schedule in which lights on and lights off corresponded to 8 am and 8 pm Eastern Standard Time, respectively. Females were inspected for the presence of a vaginal plug each morning (2-3 h after lights on) and were housed separately from the male breeder as soon as a vaginal plug was detected.

\subsection{Tissue Harvest}

For the staging of embryos, the morning of the vaginal plug formation was designated as E0.5. For staging of neonates, the date of birth was considered P0. All tissue harvests were performed between zeitgeber time (ZT) 11 and 12, at the end of the light phase. Timed pregnant females were killed by cervical dislocation and their embryos were quickly 
extracted and placed in ice-cold, RNase-free PBS. Embryos were decapitated and their heads were fixed in RNase-free $4 \%$ paraformaldehyde (PFA) in PBS overnight at $4{ }^{\circ} \mathrm{C}$, washed in diethyl pyrocarbonate (DEPC)-treated PBS, and cryoprotected in 30\% sucrose in PBS for at least $24 \mathrm{~h}$. Tissues were then frozen in Tissue Tek Optimal Cutting Temperature (OCT) embedding media (Sakura Finetek, Torrance, CA, USA) with dry ice and cut into $14 \mu \mathrm{m}$ thin sections using the CryoStar NX50 Cryostat (Thermo Scientific, Waltham, MA, USA). Sections were thaw mounted on SuperFrost Plus slides (Fisher Scientific, Waltham, MA, USA). Slides were left in $-20{ }^{\circ} \mathrm{C}$ for $2 \mathrm{~h}$, and then stored at $-80{ }^{\circ} \mathrm{C}$ until further processing.

To examine bromodeoxyuridine (BrdU) retention and EYFP expression in P0 mice, animals were decapitated, and their brains were rapidly dissected and fixed in $4 \%$ PFA in PBS overnight at $4{ }^{\circ} \mathrm{C}$. Afterwards, they were washed in PBS and cryoprotected in $30 \%$ sucrose in PBS for at least $24 \mathrm{~h}$. Tissues were cut into $30 \mu \mathrm{m}$ or $40 \mu \mathrm{m}$ thin sections using a freezing microtome (Leica Microsystems, Wetzlar, Germany), and stored in 30\% sucrose at $4{ }^{\circ} \mathrm{C}$ until further use. For in situ hybridization, $\mathrm{P} 0$ mice were decapitated, and their brains were fixed in RNase-free $4 \%$ PFA in PBS overnight at $4{ }^{\circ} \mathrm{C}$, washed in DEPC-treated PBS, and cryoprotected in 30\% sucrose in PBS for at least $24 \mathrm{~h}$. Tissues were processed and stored as described above for embryonic brain tissues.

P7 and adult brains were dissected and sectioned in ice-cold oxygenated media with an oscillating tissue slicer (Electron Microscopy Sciences, Hatfield, PA, USA) to obtain $800 \mu \mathrm{m}$ thick coronal slices. Tissue slices were fixed in 4\% PFA in PBS (pH 7.4) for $6 \mathrm{~h}$ at room temperature, cryoprotected in $30 \%$ sucrose in PBS at $4{ }^{\circ} \mathrm{C}$ overnight, cut into $30 \mu \mathrm{m}$ (adult) and $40 \mu \mathrm{m}$ (P7) thin sections using a freezing microtome (Leica Microsystems), and stored in $30 \%$ sucrose at $4{ }^{\circ} \mathrm{C}$ until further use.

\subsection{Immunofluorescence (IF)}

Tissues were washed $5 \times 5 \mathrm{~min}$ in PBS (pH 7.4) with $0.1 \%$ Triton X-100 (PBST), incubated for $1 \mathrm{~h}$ at room temperature (RT) in blocking solution (10\% heat inactivated horse serum (Wisent Inc., Saint-Jean-Baptiste, QC, Canada) in PBST), and incubated overnight at $4{ }^{\circ} \mathrm{C}$ in fresh blocking solution containing the primary antibody (Goat anti-GFP, 1:1000, Eusera, Edmonton, AB, Canada, EU3; Rabbit anti-SOX2, 1:300, Abcam, Cambridge, UK, ab97959). The next day, tissues were washed $5 \times 5$ min with PBST and incubated for $2 \mathrm{~h}$ at RT, protected from light, with the appropriate secondary AlexaFluor antibody (1:1000, ThermoFisher Scientific, Waltham, MA, USA) diluted in blocking solution. Sections were washed $5 \times 5$ min with PBST, incubated for $10 \mathrm{~min}$ in DAPI $(1 \mu \mathrm{g} / \mathrm{mL}$, SigmaAldrich, St. Louis, MO, USA) diluted in PBS, washed twice in PBS, and mounted onto glass microscope slides. Slides were coverslipped with Vectashield Mounting Medium (Vector Biolabs, Malvern, PA, USA) and sealed with nail polish.

\subsection{Bromodeoxyuridine Labeling}

Pregnant female mice were injected intraperitoneally with BrdU $(100 \mathrm{mg} / \mathrm{kg}$, SigmaAldrich, B5002) at the specified embryonic age between ZT9 and ZT10. Embryos and pups were fixed and sectioned as described above. Tissues were treated with $2 \mathrm{~N} \mathrm{HCl}$ for 25 min at $55{ }^{\circ} \mathrm{C}$, washed 3 times in PBS at room temperature, and incubated in $10 \%$ heat inactivated horse serum (Wisent Inc.) in PBST for $1 \mathrm{~h}$. The slides were incubated overnight at $4{ }^{\circ} \mathrm{C}$ in fresh blocking solution containing rat anti-BrdU antibody (1:1000, Bio-Rad Laboratories, Hercules, CA, USA, OBT0030G) and rabbit anti-MeCP2 antibody (1:200, EMD Millipore, Burlington, MA, USA, 07-013). The next day, tissues were washed $5 \times 5$ min with PBST and incubated for $2 \mathrm{~h}$ at RT in the dark with the appropriate secondary AlexaFluor antibody (1:1000, ThermoFisher Scientific) diluted in blocking solution. Sections were washed $5 \times 5$ min with PBST, followed by one PBS rinse. Free-floating sections from P0 and P7 animals were mounted onto glass microscope slides. Slides were coverslipped with Vectashield Mounting Medium (Vector Biolabs) and sealed with nail polish. 


\subsection{RNAscope in situ Hybridization (ISH)}

The in situ hybridization (ISH) probes that were used to visualize mRNA expression were purchased from Advanced Cell Diagnostics (Newark, CA, USA). The probes used in this study can be found in Table 2. The RNAscope Multiplex Fluorescent Reagent Kit v2 (Cat \#323100, Advanced Cell Diagnostics, Newark, CA, USA) was used according to the manufacturer's instructions for fixed frozen sections with some modifications. Slides were washed in PBS for $5 \mathrm{~min}$, baked at $60{ }^{\circ} \mathrm{C}$ for $30 \mathrm{~min}$, fixed with $4 \%$ PFA in PBS for 90 min at RT, dehydrated in increasing concentrations of ethanol $(50 \%, 70 \%, 100 \%$, and $100 \%$ ), and baked again at $60{ }^{\circ} \mathrm{C}$ for $10 \mathrm{~min}$. Slides were then treated with RNAscope hydrogen peroxide for $10 \mathrm{~min}$ at RT. Antigen retrieval was performed by placing slides into mildly boiling RNAscope target retrieval reagent for $5 \mathrm{~min}$ and then washing the slides in distilled water for $15 \mathrm{~s}$, followed by $100 \%$ ethanol for $3 \mathrm{~min}$. Slides were dried and permeabilized with RNAscope Protease III for $30 \mathrm{~min}$ at $40{ }^{\circ} \mathrm{C}$. Next, slides were rinsed with distilled water followed by probe incubation for $2 \mathrm{~h}$ at $40{ }^{\circ} \mathrm{C}$. Afterwards, slides were incubated with a series of amplifier probes and HRP solution at $40{ }^{\circ} \mathrm{C}$ (AMP1, $30 \mathrm{~min}$; AMP2, 30 min; AMP3, 15 min; HRP-C1, HRP-C2 or HRP-C3, 15 min) with $2 \times 2$ min of washes with RNAscope wash buffer in between each step. Slides were incubated with Opal dyes (Akoya Biosciences, Menlo Park, CA, USA) diluted in TSA buffer for $30 \mathrm{~min}$ at $40^{\circ} \mathrm{C}$. HRP activity was then blocked, sections were counterstained with DAPI, and slides were coverslipped with Vectashield Mounting Medium (Vector Biolabs). Positive and negative control probes (identifier: 320881 and 320871) were used in all experiments to ensure RNA quality and probe specificity.

\subsection{Image Acquisition and Quantification}

Images were acquired using a Zeiss Axio Observer Z1 inverted microscope equipped with a Laser Scanning Microscope (LSM) 700 module for confocal images and an AxioCam MRm Rev.3 monochromatic digital camera (Zeiss, Jena, Germany) for bright-field pictures, with the Zen 2010 software (Zeiss). Identical settings were used for imaging samples within each experiment (gain, pinhole, filter sets for confocal microscopy). Confocal images were acquired in separate channels for each fluorophore. All image analyses were performed on ImageJ.

Intensity. For quantification of staining intensity, $20 \times$ confocal images of the bilateral SCN were acquired. The area of each SCN was delineated using the polygon selection tool based on the higher cell density as reflected by the DAPI staining pattern, and the average grayscale intensity was obtained using the "measure" function. Background staining was measured in a non-immunoreactive region adjacent to each SCN and subtracted from the immunoreactive intensity within the SCN.

Cell counts. For BrdU ${ }^{+}$cell count and density measurement, $20 \times$ confocal images were acquired that covered the entire surface of the bilateral SCN. Thirty- or 40- $\mu \mathrm{m}$-thick coronal sections were used for P0 and P7 mice. The SCN area for P0 and P7 mice was measured and delineated using the polygon tool based on the higher cell density as reflected by MeCP2 immunoreactivity. For E12.5, E13.5, E14.5, and E15.5 SCN, tissues were serially sectioned and every 14- $\mu$ m-thick coronal section was mounted onto pairs of microscope slides in an alternating fashion. One series of tissues (corresponding to the 1st, 3rd, 5th, etc., sections) was labelled with anti-BrdU antibody, and the other series (corresponding to the 2nd, 4th, 6th, etc., sections) was labelled with $L h x 1$ RNAscope probe. Lhx1 expression pattern was used to define the boundary of the SCN, which was then inferred to the neighboring/adjacent sections used for BrdU IHC by common hypothalamic landmarks. The total number of $\mathrm{BrdU}^{+}$cells within the SCN of 3 to 5 central coronal sections was counted manually through all z-planes by an observer blind to the genotype of the mice. The average number and density of $\mathrm{BrdU}^{+}$cells in one unilateral SCN slice from each animal was calculated. The values reported represent mean \pm SEM of 3 to 5 animals of the same experimental group (see Table 1). 
For quantification of $\mathrm{Avp}^{+}$and $\mathrm{Vip}^{+}$cells, $20 \times$ confocal images were acquired that covered the entire surface of the bilateral SCN from 14- $\mu \mathrm{m}$-thick coronal sections (for all age points). The $\mathrm{SCN}$ area was first measured and delineated using the polygon tool based on the higher cell density as reflected by the DAPI staining pattern. The total number of $\mathrm{Avp}^{+}$and $\mathrm{Vip}^{+}$cells within the SCN of 3 to 5 central coronal sections was counted manually through all z-planes. The average number and density of $\mathrm{Avp}^{+}$and $\mathrm{Vip}^{+}$cells in one unilateral SCN slice from each animal was calculated. The values reported represent mean \pm SEM of 3 to 5 animals of the same experimental group (see Table 2).

\subsection{Statistical Analysis}

Data were analyzed using two-tailed Student's $t$-test and two-way ANOVA with $\mathrm{R}$ version 4.0.3. Post hoc significance of pairwise comparisons was assessed using Tukey's Honest Significant Difference test with $\alpha$ set at 0.05 .

Author Contributions: Conceptualization (H.-Y.M.C.); formal analysis (A.H.C., S.W.F., S.H.); investigation (A.H.C.); writing—original draft (A.H.C.); writing—review and editing (A.H.C., O.H.M.H.A., H.-Y.M.C.); visualization (A.H.C.); supervision (H.-Y.M.C.); funding acquisition (H.-Y.M.C.). All authors have read and agreed to the published version of the manuscript.

Funding: This work was supported by operating grants to H.-Y.M.C. from the Canadian Institutes of Health Research (CIHR; grant No. PJT-166046 and PJ8-162479) and the Natural Sciences and Engineering Research Council of Canada (NSERC; grant No. RGPIN-2016-05563). H.-Y.M.C. was supported by an NSERC Tier II Canada Research Chair in Molecular Genetics of Biological Clocks. A.H.C., S.H., and O.H.M.H.A. were supported by NSERC post-graduate scholarships.

Institutional Review Board Statement: All animal handling and experimental procedures were approved by the UTM Animal Care Committee (Protocol 20011581, approved 12 March 2018), complying with guidelines established by the University of Toronto Animal Care Committee and the Canadian Council on Animal Care.

Informed Consent Statement: Not applicable.

Data Availability Statement: Data supporting reported results may be supplied upon request by authors.

Acknowledgments: The authors thank L. Martin and H.-S. Rhee for sharing reagents and equipment. Many thanks to S. Poulson and C. Cho for technical advice and assistance. The authors are grateful to all members of the Cheng lab for constructive discussion.

Conflicts of Interest: The authors declare no conflict of interest.

\section{References}

1. Inouye, S.T.; Kawamura, H. Persistence of circadian rhythmicity in a mammalian hypothalamic "island" containing the suprachiasmatic nucleus. Proc. Natl. Acad. Sci. USA 1979, 76, 5962-5966. [CrossRef]

2. Welsh, D.K.; Logothetis, D.E.; Meister, M.; Reppert, S.M. Individual neurons dissociated from rat suprachiasmatic nucleus express independently phased circadian firing rhythms. Neuron 1995, 14, 697-706. [CrossRef]

3. Gekakis, N.; Staknis, D.; Nguyen, H.B.; Davis, F.C.; Wilsbacher, L.D.; King, D.P.; Takahashi, J.S.; Weitz, C.J. Role of the CLOCK protein in the mammalian circadian mechanism. Science 1998, 280, 1564-1569. [CrossRef] [PubMed]

4. Kume, K.; Zylka, M.J.; Sriram, S.; Shearman, L.P.; Weaver, D.R.; Jin, X.; Maywood, E.S.; Hastings, M.H.; Reppert, S.M. mCRY1 and mCRY2 are essential components of the negative limb of the circadian clock feedback loop. Cell 1999, 98, 193-205. [CrossRef]

5. Bunger, M.K.; Wilsbacher, L.D.; Moran, S.M.; Clendenin, C.; Radcliffe, L.A.; Hogenesch, J.B.; Simon, M.C.; Takahashi, J.S.; Bradfield, C.A. Mop3 Is an Essential Component of the Master Circadian Pacemaker in Mammals. Cell 2000, 103, 1009-1017. [CrossRef]

6. Vitaterna, M.H.; Ko, C.H.; Chang, A.M.; Buhr, E.D.; Fruechte, E.M.; Schook, A.; Antoch, M.P.; Turek, F.W.; Takahashi, J.S. The mouse Clock mutation reduces circadian pacemaker amplitude and enhances efficacy of resetting stimuli and phase-response curve amplitude. Proc. Natl. Acad. Sci. USA 2006, 103, 9327-9332. [CrossRef]

7. Shearman, L.P; Zylka, M.J.; Weaver, D.R.; Kolakowski, L.F.; Reppert, S.M. Two period homologs: Circadian expression and photic regulation in the suprachiasmatic nuclei. Neuron 1997, 19, 1261-1269. [CrossRef]

8. Shearman, L.P.; Sriram, S.; Weaver, D.R.; Maywood, E.S.; Chaves, I.; Zheng, B.; Kume, K.; Lee, C.C.; Van Der Horst, G.T.J.; Hastings, M.H.; et al. Interacting molecular loops in the mammalian circadian clock. Science 2000, 288, 1013-1019. [CrossRef] 
9. Zheng, B.; Larkin, D.W.; Albrecht, U.; Sun, Z.S.; Sage, M.; Eichele, G.; Lee, C.C.; Bradley, A. The mPer2 gene encodes a functional component of the mammalian circadian clock. Nature 1999, 400, 169-173. [CrossRef]

10. Zheng, B.; Albrecht, U.; Kaasik, K.; Sage, M.; Lu, W.; Vaishnav, S.; Li, Q.; Sun, Z.S.; Eichele, G.; Bradley, A.; et al. Nonredundant roles of the mPer1 and mPer2 genes in the mammalian circadian clock. Cell 2001, 105, 683-694. [CrossRef]

11. Vitaterna, M.H.; Selby, C.P.; Todo, T.; Niwa, H.; Thompson, C.; Fruechte, E.M.; Hitomi, K.; Thresher, R.J.; Ishikawa, T.; Miyazaki, J.; et al. Differential regulation of mammalian Period genes and circadian rhythmicity by cryptochromes 1 and 2. Proc. Natl. Acad. Sci. USA 1999, 96, 12114-12119. [CrossRef] [PubMed]

12. Aton, S.J.; Colwell, C.S.; Harmar, A.J.; Waschek, J.; Herzog, E.D. Vasoactive intestinal polypeptide mediates circadian rhythmicity and synchrony in mammalian clock neurons. Nat. Neurosci. 2005, 8, 476-483. [CrossRef] [PubMed]

13. Maywood, E.S.; Chesham, J.E.; O’Brien, J.A.; Hastings, M.H. A diversity of paracrine signals sustains molecular circadian cycling in suprachiasmatic nucleus circuits. Proc. Natl. Acad. Sci. USA 2011, 108, 14306-14311. [CrossRef] [PubMed]

14. Mieda, M.; Ono, D.; Hasegawa, E.; Okamoto, H.; Honma, K.-I.; Honma, S.; Sakurai, T. Cellular clocks in AVP neurons of the SCN are critical for interneuronal coupling regulating circadian behavior rhythm. Neuron 2015, 85, 1103-1116. [CrossRef]

15. Albrecht, U.; Zheng, B.; Larkin, D.; Sun, Z.S.; Lee, C.C. mPer1 and mPer2 Are Essential for Normal Resetting of the Circadian Clock. J. Biol. Rhythms 2001, 16, 100-104. [CrossRef]

16. Nakamura, W.; Yamazaki, S.; Takasu, N.N.; Mishima, K.; Block, G.D. Differential response of Period 1 expression within the suprachiasmatic nucleus. J. Neurosci. 2005, 25, 5481-5487. [CrossRef]

17. Wen, S.; Ma, D.; Zhao, M.; Xie, L.; Wu, Q.; Gou, L.; Zhu, C.; Fan, Y.; Wang, H.; Yan, J. Spatiotemporal single-cell analysis of gene expression in the mouse suprachiasmatic nucleus. Nat. Neurosci. 2020, 23, 456-467. [CrossRef] [PubMed]

18. Brancaccio, M.; Patton, A.P.; Chesham, J.E.; Maywood, E.S.; Hastings, M.H. Astrocytes Control Circadian Timekeeping in the Suprachiasmatic Nucleus via Glutamatergic Signaling. Neuron 2017, 93, 1420-1435.e5. [CrossRef]

19. Todd, W.D.; Venner, A.; Anaclet, C.; Broadhurst, R.Y.; De Luca, R.; Bandaru, S.S.; Issokson, L.; Hablitz, L.M.; Cravetchi, O.; Arrigoni, E.; et al. Suprachiasmatic VIP neurons are required for normal circadian rhythmicity and comprised of molecularly distinct subpopulations. Nat. Commun. 2020, 11, 4410. [CrossRef]

20. Abrahamson, E.E.; Moore, R.Y. Suprachiasmatic nucleus in the mouse: Retinal innervation, intrinsic organization and efferent projections. Brain Res. 2001, 916, 172-191. [CrossRef]

21. Antle, M.C.; Silver, R. Orchestrating time: Arrangements of the brain circadian clock. Trends Neurosci. 2005, 28, 145-151. [CrossRef] [PubMed]

22. Cheng, M.Y.; Bullock, C.M.; Li, C.; Lee, A.G.; Bermak, J.C.; Belluzzi, J.; Weaver, D.R.; Leslie, F.M.; Zhou, Q.-Y. Prokineticin 2 transmits the behavioural circadian rhythm of the suprachiasmatic nucleus. Nature 2002, 417, 405-410. [CrossRef] [PubMed]

23. Clark, D.D.; Gorman, M.R.; Hatori, M.; Meadows, J.D.; Panda, S.; Mellon, P.L. Aberrant Development of the Suprachiasmatic Nucleus and Circadian Rhythms in Mice Lacking the Homeodomain Protein Six6. J. Biol. Rhythms 2013, 28, 15-25. [CrossRef] [PubMed]

24. Roy, A.; de Melo, J.; Chaturvedi, D.; Thein, T.; Cabrera-Socorro, A.; Houart, C.; Meyer, G.; Blackshaw, S.; Tole, S. LHX2 is necessary for the maintenance of optic identity and for the progression of optic morphogenesis. J. Neurosci. 2013, 33, 6877-6884. [CrossRef] [PubMed]

25. VanDunk, C.; Hunter, L.A.; Gray, P.A. Development, Maturation, and Necessity of Transcription Factors in the Mouse Suprachiasmatic Nucleus. J. Neurosci. 2011, 31, 6457-6467. [CrossRef] [PubMed]

26. Newman, E.A.; Kim, D.W.; Wan, J.; Wang, J.; Qian, J.; Blackshaw, S. Foxd1 is required for terminal differentiation of anterior hypothalamic neuronal subtypes. Dev. Biol. 2018, 439, 102-111. [CrossRef] [PubMed]

27. Pandolfi, E.C.; Breuer, J.A.; Nguyen Huu, V.A.; Talluri, T.; Nguyen, D.; Lee, J.S.; Hu, R.; Bharti, K.; Skowronska-Krawczyk, D.; Gorman, M.R.; et al. The Homeodomain Transcription Factors Vax1 and Six6 Are Required for SCN Development and Function. Mol. Neurobiol. 2020, 57, 1217-1232. [CrossRef]

28. Bedont, J.L.; LeGates, T.A.; Slat, E.A.; Byerly, M.S.; Wang, H.; Hu, J.; Rupp, A.C.; Qian, J.; Wong, G.W.; Herzog, E.D.; et al. Lhx1 Controls Terminal Differentiation and Circadian Function of the Suprachiasmatic Nucleus. Cell Rep. 2014, 7, 609-622. [CrossRef]

29. Zappone, M.V.; Galli, R.; Catena, R.; Meani, N.; De Biasi, S.; Mattei, E.; Tiveron, C.; Vescovi, A.L.; Lovell-Badge, R.; Ottolenghi, S.; et al. Sox 2 regulatory sequences direct expression of a $\beta$-geo transgene to telencephalic neural stem cells and precursors of the mouse embryo, revealing regionalization of gene expression in CNS stem cells. Development 2000, 127, 2367-2382. [CrossRef]

30. Hoefflin, S.; Carter, D.A. Neuronal expression of SOX2 is enriched in specific hypothalamic cell groups. J. Chem. Neuroanat. 2014 61, 153-160. [CrossRef]

31. Mercurio, S.; Serra, L.; Motta, A.; Gesuita, L.; Sanchez-Arrones, L.; Inverardi, F.; Foglio, B.; Barone, C.; Kaimakis, P.; Martynoga, B.; et al. Sox2 Acts in Thalamic Neurons to Control the Development of Retina-Thalamus-Cortex Connectivity. iScience 2019, 15, 257-273. [CrossRef] [PubMed]

32. Ferri, A.; Favaro, R.; Beccari, L.; Bertolini, J.; Mercurio, S.; Nieto-Lopez, F.; Verzeroli, C.; La Regina, F.; De Pietri Tonelli, D.; Ottolenghi, S.; et al. Sox2 is required for embryonic development of the ventral telencephalon through the activation of the ventral determinants Nkx2.1 and Shh. Development 2013, 140, 1250-1261. [CrossRef]

33. Favaro, R.; Valotta, M.; Ferri, A.L.M.; Latorre, E.; Mariani, J.; Giachino, C.; Lancini, C.; Tosetti, V.; Ottolenghi, S.; Taylor, V.; et al. Hippocampal development and neural stem cell maintenance require Sox2-dependent regulation of Shh. Nat. Neurosci. 2009, 12, 1248-1256. [CrossRef] [PubMed] 
34. Cavallaro, M.; Mariani, J.; Lancini, C.; Latorre, E.; Caccia, R.; Gullo, F.; Valotta, M.; DeBiasi, S.; Spinardi, L.; Ronchi, A.; et al. Impaired generation of mature neurons by neural stem cells from hypomorphic Sox2 mutants. Development 2008, 135, 541-557. [CrossRef]

35. Ferri, A.L.M.; Cavallaro, M.; Braida, D.; Di Cristofano, A.; Canta, A.; Vezzani, A.; Ottolenghi, S.; Pandolfi, P.P.; Sala, M.; DeBiasi, S.; et al. Sox2 deficiency causes neurodegeneration and impaired neurogenesis in the adult mouse brain. Development 2004, 131, 3805-3819. [CrossRef] [PubMed]

36. Kelberman, D.; Rizzoti, K.; Avilion, A.A.; Bitner-Glindzicz, M.; Cianfarani, S.; Collins, J.; Chong, W.K.; Kirk, J.M.W.; Achermann, J.C.; Ross, R.; et al. Mutations within Sox2/SOX2 are associated with abnormalities in the hypothalamo-pituitary-gonadal axis in mice and humans. J. Clin. Investig. 2006, 116, 2442-2455. [CrossRef]

37. Cheng, A.H.; Bouchard-Cannon, P.; Hegazi, S.; Lowden, C.; Fung, S.W.; Chiang, C.K.; Ness, R.W.; Cheng, H.Y.M. SOX2-Dependent Transcription in Clock Neurons Promotes the Robustness of the Central Circadian Pacemaker. Cell Rep. 2019, 26, 3191-3202.e8. [CrossRef]

38. Cheng, A.H.; Bouchard-Cannon, P.; Ness, R.W.; Cheng, H.Y.M. RNA-sequencing data highlighting the time-of-day-dependent transcriptome of the central circadian pacemaker in Sox2-deficient mice. Data Br. 2019, 24, 103909. [CrossRef]

39. Srinivas, S.; Watanabe, T.; Lin, C.S.; William, C.M.; Tanabe, Y.; Jessell, T.M.; Costantini, F. Cre reporter strains produced by targeted insertion of EYFP and ECFP into the ROSA26 locus. BMC Dev. Biol. 2001, 1, 4. [CrossRef]

40. Kabrita, C.S.; Davis, F.C. Development of the mouse suprachiasmatic nucleus: Determination of time of cell origin and spatial arrangements within the nucleus. Brain Res. 2008, 1195, 20-27. [CrossRef]

41. Achim, K.; Salminen, M.; Partanen, J. Mechanisms regulating GABAergic neuron development. Cell. Mol. Life Sci. 2014, 71, 1395-1415. [CrossRef] [PubMed]

42. Ahern, T.H.; Krug, S.; Carr, A.V.; Murray, E.K.; Fitzpatrick, E.; Bengston, L.; McCutcheon, J.; De Vries, G.J.; Forger, N.G. Cell death atlas of the postnatal mouse ventral forebrain and hypothalamus: Effects of age and sex. J. Comp. Neurol. 2013, 521, 2551-2569. [CrossRef] [PubMed]

43. McNeill, D.S.; Sheely, C.J.; Ecker, J.L.; Badea, T.C.; Morhardt, D.; Guido, W.; Hattar, S. Development of melanopsin-based irradiance detecting circuitry. Neural Dev. 2011, 6, 8. [CrossRef] [PubMed]

44. Lodato, M.A.; Ng, C.W.; Wamstad, J.A.; Cheng, A.W.; Thai, K.K.; Fraenkel, E.; Jaenisch, R.; Boyer, L.A. SOX2 Co-Occupies Distal Enhancer Elements with Distinct POU Factors in ESCs and NPCs to Specify Cell State. PLoS Genet. 2013, 9, e1003288. [CrossRef] [PubMed]

45. Gascón, S.; Murenu, E.; Masserdotti, G.; Ortega, F.; Russo, G.L.; Petrik, D.; Deshpande, A.; Heinrich, C.; Karow, M.; Robertson, S.P.; et al. Identification and Successful Negotiation of a Metabolic Checkpoint in Direct Neuronal Reprogramming. Cell Stem Cell 2016, 18, 396-409. [CrossRef] [PubMed]

46. Hyodo, S.; Yamada, C.; Takezawa, T.; Urano, A. Expression of provasopressin gene during ontogeny in the hypothalamus of developing mice. Neuroscience 1992, 46, 241-250. [CrossRef]

47. Jing, X.; Ratty, A.K.; Murphy, D. Ontogeny of the vasopressin and oxytocin RNAs in the mouse hypothalamus. Neurosci. Res. 1998, 30, 343-349. [CrossRef]

48. Ban, Y.; Shigeyoshi, Y.; Okamura, H. Development of vasoactive intestinal peptide mRNA rhythm in the rat suprachiasmatic nucleus. J. Neurosci. 1997, 17, 3920-3931. [CrossRef]

49. Gross-Thebing, T.; Paksa, A.; Raz, E. Simultaneous high-resolution detection of multiple transcripts combined with localization of proteins in whole-mount embryos. BMC Biol. 2014, 12, 55. [CrossRef]

50. Wang, F.; Flanagan, J.; Su, N.; Wang, L.-C.; Bui, S.; Nielson, A.; Wu, X.; Vo, H.-T.; Ma, X.-J.; Luo, Y. RNAscope: A novel in situ RNA analysis platform for formalin-fixed, paraffin-embedded tissues. J. Mol. Diagn. 2012, 14, 22-29. [CrossRef]

51. Boehler, N.A.; Fung, S.W.; Hegazi, S.; Cheng, A.H.; Cheng, H.M. Sox2 Ablation in the Suprachiasmatic Nucleus Perturbs Anxietyand Depressive-like Behaviors. Neurol. Int. 2021, 13, 541-554. [CrossRef] [PubMed] 